\title{
Colours and metallic sheen in beetle shells - A biomimetic search for material structuring principles causing light interference
}

\author{
Lenau, Torben Anker; Barfoed, Michael
}

Published in:

Advanced Engineering Materials

Link to article, DOI:

10.1002/adem.200700346

Publication date:

2008

Document Version

Peer reviewed version

Link back to DTU Orbit

Citation (APA):

Lenau, T. A., \& Barfoed, M. (2008). Colours and metallic sheen in beetle shells - A biomimetic search for material structuring principles causing light interference. Advanced Engineering Materials, 10(4), 299-314. https://doi.org/10.1002/adem.200700346

\section{General rights}

Copyright and moral rights for the publications made accessible in the public portal are retained by the authors and/or other copyright owners and it is a condition of accessing publications that users recognise and abide by the legal requirements associated with these rights.

- Users may download and print one copy of any publication from the public portal for the purpose of private study or research.

- You may not further distribute the material or use it for any profit-making activity or commercial gain

- You may freely distribute the URL identifying the publication in the public portal 
COLOURS AND METALLIC SHEEN IN BEETLE SHELLS

\title{
- A BIOMIMETIC SEARCH FOR MATERIAL STRUCTURING PRINCIPLES CAUSING LIGHT INTERFERENCE
}

\author{
Dr. Torben Lenau and Mr. Michael Barfoed \\ Department of Manufacturing Engineering and Management \\ Technical University of Denmark \\ Building 424 \\ DK - 2800 Lyngby, Denmark \\ Email: lenau@ipl.dtu.dk
}

Printed in Advanced Engineering Materials 2008, 10, no. 4, p. 299-314

\begin{abstract}
Summary
Visual aesthetic has always played a vital role for the success of many products. This includes colours and glossiness and metal appearance which is often achieved using surface coatings. Present coating techniques do, however, have limitations. It is difficult to reach very bright and brilliant colours, colours tend to fade over time and many of the materials and coating technologies pollute and have other environmental problems. Beetles in nature have many of the desired properties: They have appealing brilliant colours and some even with metallic appearance. It is noticeable that the colours are long lasting as some of the beetles we have studied at the zoological museum are more than 200 years old and have colours and brightness as if they were still alive. Furthermore, the beetles in nature are part of sustainable ecosystems, which means that they are made from renewable materials that are broken down and recycled when the beetle dies. Beetles also possess another and very attractive property: Their metallic look originates from structures in organic materials which is both electrically and thermal insulating. The industrial perspective is to be able to manufacture products with attractive metallic surfaces that do not feel so cold to touch as their metallic counterparts and that do not represent an electrical shock hazard.
\end{abstract}

The present paper presents a cross disciplinary biomimetic review of research results that explain the materials and nanostructure in beetle shells and the mechanisms that generate them. The metallic and bright colours of beetle shells are structural colours deriving from at least two different internal shell structures with different light reflecting properties. One nano-structure is the multilayer stack which is composed of layered pairs with different refractive indices and it can reflect all colours of the spectrum. Another structure is the Bouligand structure that resembles cholesteric liquid crystals with a twist of layer directions reflecting circular polarized light. The colours of the transparent structures are structural colours caused by light interference. The shells are mostly made of cross linked chitin (a polysaccharid) and proteins. The basic ingredients of the structure are released by living epidermal cells in a fluid deposition zone where after they self assembly to a layered mesh. That the structure is formed by self assembly gives the hope that similar structures with the same optical properties also can be formed artificially without templates.

The paper also presents a review of existing applications with structural colours obtained by nanostructured surfaces and describes the goals for further research required in order to achieve industrially manufactured beetle-like surfaces with properties such as sustainability, aesthetics, insulation, durability etc. 
Key-words: optical nanotechnology, aesthetics, biomimetics, sustainability. 


\section{INTRODUCTION}

Some beetles and other insects exhibit brilliant and attractive colours and metallic reflectance (figure 1A). These optical phenomena are caused by the micro- and nanostructure in the hard insect shell also called the exoskeleton or the cuticle. The optical phenomena have been studied for more than a century, however, the idea to construct similar structures artificially is much more recent. With the advent of electron microscopy, detailed information about the microstructures of the cuticle has arisen.
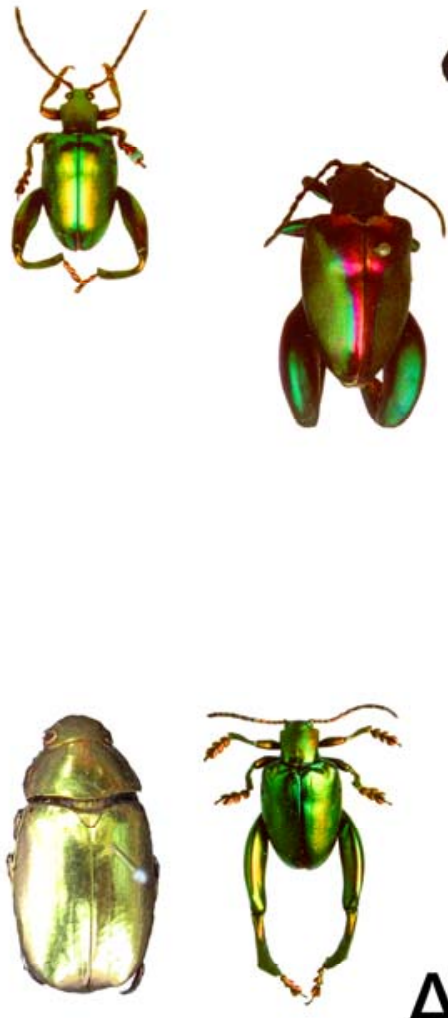
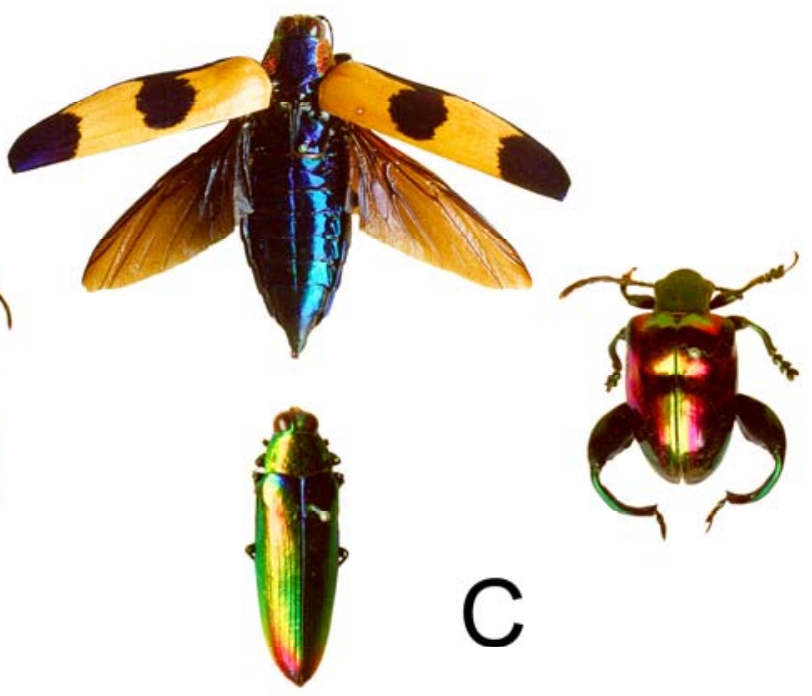
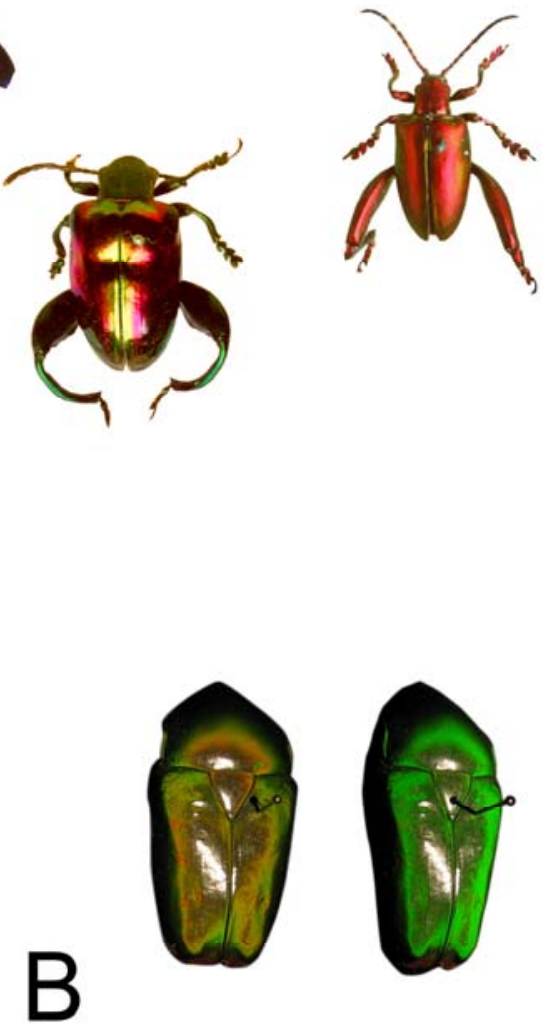

Figure 1. Colours and metallic sheen in beetle shells.

A. Two beetles with metallic green (Sagra femorata) and gold appearance (Plusiotis resplendens).

B. Blueshift seen for a Dicranorrhina micans. The colour changes from orange/yellow (left) at $\theta=10^{\circ}$ to bright green (right) for $\theta=35^{\circ}$.

C. Beetles showing a range of colours and appearances ranging from highly metallic to different degrees of matte sheen.

This paper presents the results from a comprehensive literature study. The goal has been to facilitate the understanding of the colour generating structure in beetles. The literature covers micro- and nanostructures not only in insect shells but also other arthropods like lobsters and crayfish. The whole insect cuticle including the wings is built from basically the same transparent material.

Several different colour generating micro- and nanostructures in beetles and other insects are known e.g. surface ridges ${ }^{[1,2,3]}$, micro lenses ${ }^{[4,5,6]}$ and photonic crystals ${ }^{[7,8,9]}$. These structural colour generating features are often combined with pigment colours ${ }^{[10,11]}$ or sometimes with layers of other 
high reflective crystals e.g. uric acid ${ }^{[12]}$. This present study focuses on the internal fibrous layered structures of the cuticle. We have also studied how the cuticle is formed, from the synthesis of chitin and protein in the epidermal cells to the formation of chitin crystals, over chitin fibrils and fibres to the final layout of the fibres in the cuticle.

Much of the work explaining the cuticle microstructure rely on interpretations of the empirical data, since the "units of colour generation" are sub microscopic. Electron micrographs are open for more than one interpretation and they only represent a small section of the complete cuticle and the chemical analysis by its nature often is structure destroying.

Despite the restrains of the analyses, two basic and different structural models have been identified to explain many of the interference colour phenomena seen:

1) The observed colour phenomena are caused by a multilayer structure with alternating high and low refraction indices. These structures do not change the orientation of polarized light.

2) The observed colour phenomena are explained by a "twisted" multilayer chitin rich structure. The chitin molecules are predominantly arranged helical ("Bouligand") and behave similar to liquid crystals. These structures reflect circularly polarized light.

Both models can explain narrow band and broadband (metallic) reflection. The "twisted" Bouligand structures are used to explain why the golden beetle seen in figure 1A, can have a so-called optically active surface, which reflect and change the plane of polarized light. The multilayer structure does not rotate the polarization plane of the light, and is referred to as an optically inactive surface $^{[13]}$.

The 2 structures are both very regular and explain the high reflectivity. However, most insects with metallic appearance exhibit both specular metallic reflection and diffusive reflection. Kinoshita \& Yoshioka ${ }^{[14]}$ explains the phenomenon as a combination of regularity with irregularity within the structure. For beetles this can be a multilayer structure combined with irregular surface textures that breaks the flatness of the reflector.

A distinct feature of structural colours is their angle dependency. The observed colour changes dependent on the viewing angle. This is also called iridescence. A very regular structure will be strongly iridescent but the amount of iridescence will decrease when different types of irregularity are present in the structure. Irregularities could be that the layer thickness varies down through the structure or that the reflector is curved.

A natural question is why the beetles have such conspicuous appearance which seems far from the camouflage look of other insects. The iridescent and metallic coloured beetles are most common in the tropical rainforests of Southeast Asia, South America and Australia ${ }^{[15]}$. These forests are characterized of being very dark at the forest floor. It seems that there is an intense fight for light, materialized in elaborate multi species leaf ornamentation wherever light strikes. Within these forests light only comes in narrow and short lasting specs. Exactly this might be the reason why it is biological successful to have high reflecting colours. To avoid predators one technique is "flash colouration". When a reflective beetle moves between light and dark, the result is a high visual contrast which confuses the predator. Of course it also helps to reflect the surroundings ${ }^{[16]}$. The 
coloration of other beetles typically allows them "to disappear into their environment" by matching dominant colour patterns ${ }^{[15]}$.

The survey presented in this paper is part of a present research project where the purpose is to understand the colour generating structures of beetles and to examine if it is possible to mimic such structures and make similar solutions artificially. The perspective is that such a new surface technology can compete with conventional painting and metal plating technologies and offer more brilliant and long lasting surfaces and be a more environmentally friendly solution. Since the beetles are recycled in the ecosystem they are part of, it seems likely that the same environmental performance can be achieved if similar materials and structures are used. The project will search for alternative coating principles and materials in order to obtain the vivid colour and metallic effects seen in the beetle exoskeleton.

A promising perspective is the replacement of traditional metal coating techniques like electroplating, chemical plating, PVD and vacuum-metallization. All of these techniques apply thin layers of metal onto other substrates which can be polymers, ceramics and natural materials from plants or animals (e.g. cotton or leather). A consequence of metal plating is that the materials become much better electric and thermal conductors. Since the materials that will be used for the beetle inspired coating can be dielectric a perspective is that surfaces with metal appearance can be made electric and thermal insulating. This will open for a broad range of applications within everyday products, automotive, entertainment and communication devises and medical appliances.

The metal-look appearance is caused by a broad band specular spectral reflectance. Similar structures can reflect narrow-band light which can have larger reflectance than what can be achieved with pigment based colouration of surfaces. The perspectives are brighter colours and reduced material consumption for the coatings.

From an environment and resource view point a perspective is that raw materials can be obtained from chitin-rich waste products from the shell-fish industry, e.g. chitosan.

\section{THE FORMATION OF THE CUTICLE AND ITS MICROSTRUCTURE}

The beetle cuticle serves a number of purposes ${ }^{[13,17,18,19]}$. It acts as the very sophisticated and complicated integument that completely covers the insect's body which has special barrier properties that not only protects its bearer from impact shock, but also from radiation and harmful micro organisms. It also forms the exoskeleton that gives stiffness and strength and serves as attachment site for muscles. Sense organs and fluid canals penetrate the cuticle and allows for exchange of signals and substances with the surrounding environment. The cuticle is produced layer by layer from various materials segregated by the underlying living epidermal cells ${ }^{[13,20,21,22,23]}$. The individual layers are modified over time causing changes in thickness, chemical composition and optical properties. Chitin is a dominant component in many of the layers, but the cuticle is a composite structure also including many other materials such as various proteins, melanin, lipids, and others.

The many layers in the beetle cuticle are normally described from their position in different sections as illustrated in figure 2. From the outside to the inwards the overall sections include the epicuticle, the exocuticle and the endocuticle. The later two are together also called the procuticle. 


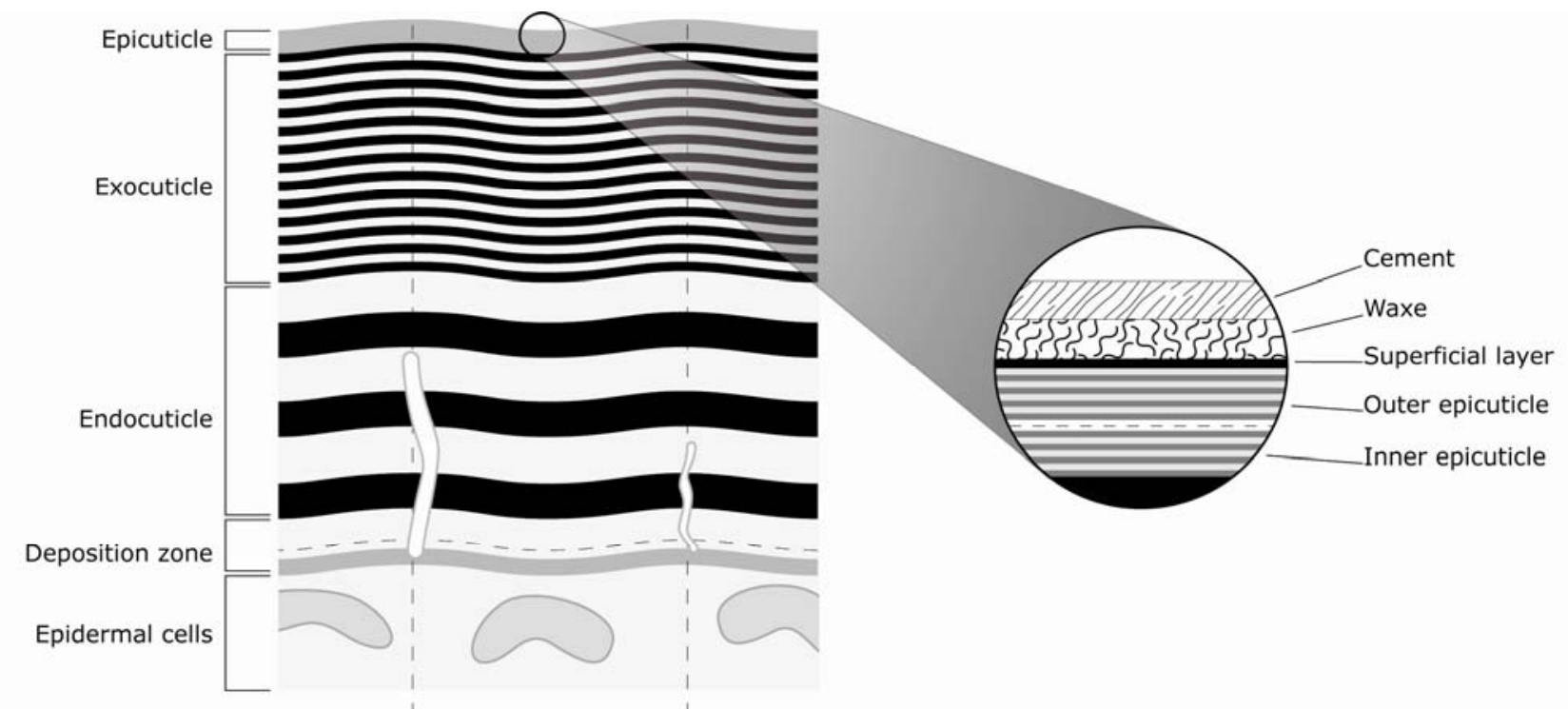

Figure 2. Enlarged cross section of a beetle cuticle showing the most important layers.

\subsection{The epicuticle}

The outermost part - the epicuticle - is defined by its position in the cuticle and the lack of chitin material. Materials include proteins, lipids, lipoproteins and dihydroxyphenols. Both the epicuticle and the exocuticle go through a tanning process after formation, which makes them stiffer and more chemically stable, and gives them an opaque brownish colour. The epicuticle is typically about 1-2 $\mu \mathrm{m}$ thick and consists of the outer epicuticle (also called the cuticulin) and the inner epicuticle. The epicuticle is covered with thin layers of wax and cement. While the epicuticle is generated before the ecdysis (the shell shift), the wax and cement layers are secreted after formation of the cuticle through the pore canals ${ }^{[13,19,25]}$.

The colour generating mechanism found in the epicuticle is a multilayer reflector with 5-8 layers of alternating electron dense and electron lucent layers with a unit-layer thickness of $60-160 \mathrm{~nm}^{[25,26]}$. Schultz and Rankin ${ }^{[25]}$ studied Tiger beetles of the genus Cicendela and distinguished the epicuticle layer from the chitinous procuticle chemically by its solubility in dilute $\mathrm{KOH}$. Colours from different species varied between metallic brick red, iridescent blue-green and brown. Kurachi ${ }^{[26]}$ studied leaf beetles Plateumaris sericea and identified the epicuticle as the colour producing layer by physical scratching and by comparing layer thicknesses from specimens with different colours. Colours from different specimens varied between blue, bronze and red. The observed colour of individual beetles changed little with changes in the angle of incidence (missing iridescence). It is proposed that this property is caused by the curvature of the small integuments and the corrugations and punctures of the beetle surface.

\subsection{The exocuticle}

The exocuticle is a fibrillar mesh of protein and chitin crystallites with relatively little fluid and is typically in the region of $100 \mu \mathrm{m}$ thick. The chitin crystallites are arranged helicoidally throughout the exocuticle. The tanning and sclerotization (hardening) of the exocuticle distinguishes it from the endocuticle together with differences in the helical pitch and individual layer thickness ${ }^{[13,27]}$. 
Colour generating structures are found in the exocuticle by several studies.

Neville ${ }^{[13]}$ describes the study of Heterorrhina africana and Heterorrhina elegans which exhibits a uniform green colour. The exocuticle has a lamelar structure with alternating dark and light layers when seen in an electron microscope. Neville proposes that the reflector is a multilayer interference reflector based on the following argument. When a piece of elytral cuticle (part of the wing) for $H$. africana was plasticized in a boiling potassium hydroxide solution it swelled and the colour changed to red. When applying suitable pressure to the surface it produced a blue colour in the middle of the depression with colours grading through the spectrum up to red in the undeformed regions. Layer thickness was measured on the micrographs to $82 \mathrm{~nm}$ and $103 \mathrm{~nm}$. Given the observed colour of $570 \mathrm{~nm}$ (viewed normally) refractive indices of 1.75 and 1.38 are calculated. Neville notice that the ratio in thickness of the 2 kinds of layers varies between 0.5 and 1.0 and wonder how this can explain the uniform green colour. Seen in the view of later findings this irregularity could be part of the explanation of the uniform colour.

Vigneron et.al ${ }^{[28]}$ describes a multilayer structure found in the ventral side of a wood boring beetle Chrysochroa vittata from the Buprestidae family causing a red colour changing to green in more grazing viewing angles. The layered structure is identified using SEM-microscopy and has 20 layers with a unit thickness of $204 \mathrm{~nm}$. The layers are located in the outer exocuticle which propose a content of chitin. Based on an optical model the structure is proposed to be made from alternating thick layers of chitin $(\mathrm{t}=194 \mathrm{~nm}, \mathrm{n}=1,56)$ and very thin layers of air $(\mathrm{t}=10 \mathrm{~nm}, \mathrm{n}=1)$.

Parker et al. ${ }^{[29]}$ studied the elytra (the cover wings) of 2 different beetles namely a green Calloodes grayanus and a golden Anoplagnathus parvulus using both SEM and TEM electron microscopy. C. grayanus had 12 layers in the exocuticle each with a $200 \mathrm{~nm}$ thick and a $50 \mathrm{~nm}$ thin section. A. Parvulus had a so called chirped stack of layers with pair wise thicker layers in the top of the elytra and thinner layers in the bottom. The difference in layer thickness should result in the reflection of many different wavelengths giving the golden metallic appearance. The epicuticle was not structured in layers in either of the 2 beetles.

Mossakowski ${ }^{[30]}$ measured the elytral cuticle of a red and a green tiger beetle Cicendela campestris and the red and green striped buprestid beetle Chrysochroa vittata using TEM and SEM electron microscopy. The species show a bilayer thickness of $165 \mathrm{~nm}$ (green) and $190 \mathrm{~nm}$ (red). There were between 3 and 10 bilayers. C. vittata exhibits colour changes for different viewing angles while there is no colour change for C. campestris. The colour change is expected for structural colours, and the lack of this feature is explained by a scalloped structure of the surface. The observed colours can only be verified by calculations from the measured layer thicknesses if either very high refractive indices are used or if a shrinkage caused by preparation or electron beam of $10-15 \%$ is assumed.

Durrer ${ }^{[31]}$ studied the surface of the elytra of Euchroma gigantea L showing red and green structural colours. The structure is found to be 5 melamin layers which are $60-80 \mathrm{~nm}$ thick embedded in chitin at a regular distance at $60 \mathrm{~nm}$. Refractive indices are estimated to 2 for melamin and 1,5 for chitin.

Caveney and Neville ${ }^{[11,12,32]}$ describe the study of Plusiotis resplendens that has the colour of burnished brass using TEM. The section responsible for the metal appearance has a thickness of 22 $\mu \mathrm{m}$, including a single $1,8 \mu \mathrm{m}$ thick layer and 95 thinner layers in the exocuticle. The apparent 
layers are actually a helicoidal structure and a set of dark and light layers as seen in the micrographs equals a half turn (a half pitch) of the helix. P. resplendens reflects circular polarized light. Refractive index values were determined using a series of known refractive index fluids. Refractive indices for the birefringent helical structure are found to be 1,700 and 1,603.

\subsection{The endocuticle}

The endocuticle is a less dense matrix with relatively more fluid ${ }^{[33]}$. Before the ecdysis, chitin degrading (chitinolytic) enzymes are released into the endocuticle ${ }^{[34]}$. Apparently only the endocuticle is broken down and reabsorbed. The outer hardened parts (the exocuticle) are thrown away with the ecdysis ${ }^{[13]}$.

Hinton $^{[35]}$ studied the golden tortoise beetle Apistomorpha tecta. The many layers $(44 \times 2)$ are placed immediately above the epidermis, which means in the endocuticle. A. tecta can change its colour when irritated from golden to reddish copper in about 2 minutes. Hinton explains the colour change by a changed liquid content in interference layers. A very little angle sensitivity is explained with the combination of many layers $(44 \times 2)$ and a high mean refractive index of the thin layer system.

Neville ${ }^{[11]}$ follows up on Hintons study of $A$. tecta. He concludes that the reflective part of the cuticle is placed in the endocuticle for 2 reasons. Firstly are the metallic colours first seen after 3-4 days after adult emergence, indicating that the colour layers are deposited after ecdysis. Secondly is the brightness of the metallic colour reduced dramatically when the adult beetle is subjected to starvation. This can be caused by resorption of some of the endocuticular layers. A. tecta furthermore looses its metallic colour when it dies so museum specimens appear opaque brown.

\subsection{Generation of the beetle cuticle}

Insects surrounded by their stiff cuticle can only grow to a limited extend - and only inwards. The growth in size thus only takes a leap around the ecdysis period both for larval instars and sometimes adults. The insect grows by breaking and throwing of the old cuticle and filling out its new membranes to its new size. After this short period the shield gets continually stiffer until the next ecdysis $^{[13,18,27,36,37,38]}$.

The art of shell shift - ecdysis - is to be able to open up "the old suit" around all organs penetrating the cuticle and loosen its attachment to the under laying structures. This process involves hundreds of elements and is so difficult that several percent of the insects dies during ecdysis ${ }^{[37]}$.

Before the ecdysis the insects change behaviour. They stop to feed and search sheltered places. They rest as the inner endocuticle dissolves. Then contractions begin and become rhythmical ending in the shedding of the old shield. Another period of rest follows as the new soft cuticle hardens and sometimes also gets its colours $^{[3,11]}$. After this the insects feeds again ${ }^{[18,37]}$.

Just before the ecdysis a new epicuticle is formed right over the epidermal cells. After the ecdysis, the new epicuticle becomes the outermost layer. The underside of this becomes the starting point of the new exocuticle ${ }^{[13,37,38]}$. 
Schultz and Rankin ${ }^{[39]}$ studied the developmental changes in the interference reflectors of Tiger Beetles (Cicindela). Elytral cuticle was cut from the beetle at 3 stages of evolution: From the pupae 4 days before ecdysis, $12 \mathrm{~h}$ after the ecdysis and 14 days after the moult. The reflected colours were compared with the structures seen in TEM electron micrographs. After ecdysis the white elytra gradually darkened and displayed first a distinctive violet hue that later changed to blue and green. The colour generating structure was located to the epicuticle which had a fully developed layer structure before ecdysis. However, the thickness of the layers increased after ecdysis just as the electron density. It is assumed that the epicuticular layers hold a precurser that is converted to a more electron dense substance by segregation of an enzyme via the pore canals.

The material for the formation of the cuticle is made by the epidermal cells and released into the fluid of the lower endocuticle where it is assumed that all following structuring to a 3 dimensional architecture occur as a process of self assembly ${ }^{[40]}$. However, if there is no coordinated growth between the fluid and chitin assembly into "broad cables" the whole matrix formation becomes disrupted with no regular formation of layers ${ }^{[18,41]}$.

In many beetles the horizontal borders of each of the epidermal cells, at the time of epicuticle formation, can be seen as corresponding polygons on the surface of the cuticle. These polygons are often hexagonal and are usually $7-20 \mu \mathrm{m}$ wide ${ }^{[2]}$. The surface of each epidermal cell is highly folded resulting in numerous papillary structures or finger like protrusions called microvilli. These further seems to be arranged in an ordered fashion ${ }^{[42,43]}$ securing an even production of e.g. chitin crystals to the fluid space between the microvilli and the underside of the above lying cuticle ${ }^{[18]}$. The microvilli might even be arranged in small groups of about 19-25 protrusions. It may therefore produce the same number of chitin chains simultaneously that together forms the so called chitin crystals $^{[44]}$ (figure 3 ). These crystals are wrapped with protein ${ }^{[45,46]}-$ and as such they form a new entity - long threads also called nanofibrils with a diameter of approximately 5-6 $\mathrm{nm}$ and a length of about $300 \mathrm{~nm}^{[44,47]}$. According to Neville ${ }^{[48]}$ all crystals of a cuticle layer of an insect will always have the crystals ordered with regard to a main orientation. Neville further calls the typical structure of the adult beetle endocuticle for "pseudo-orthogonal". In this structure layers with parallel crystals and oriented at an angle of about $90^{\circ}$ are connected by approximately a quarter-turn of a helix. 


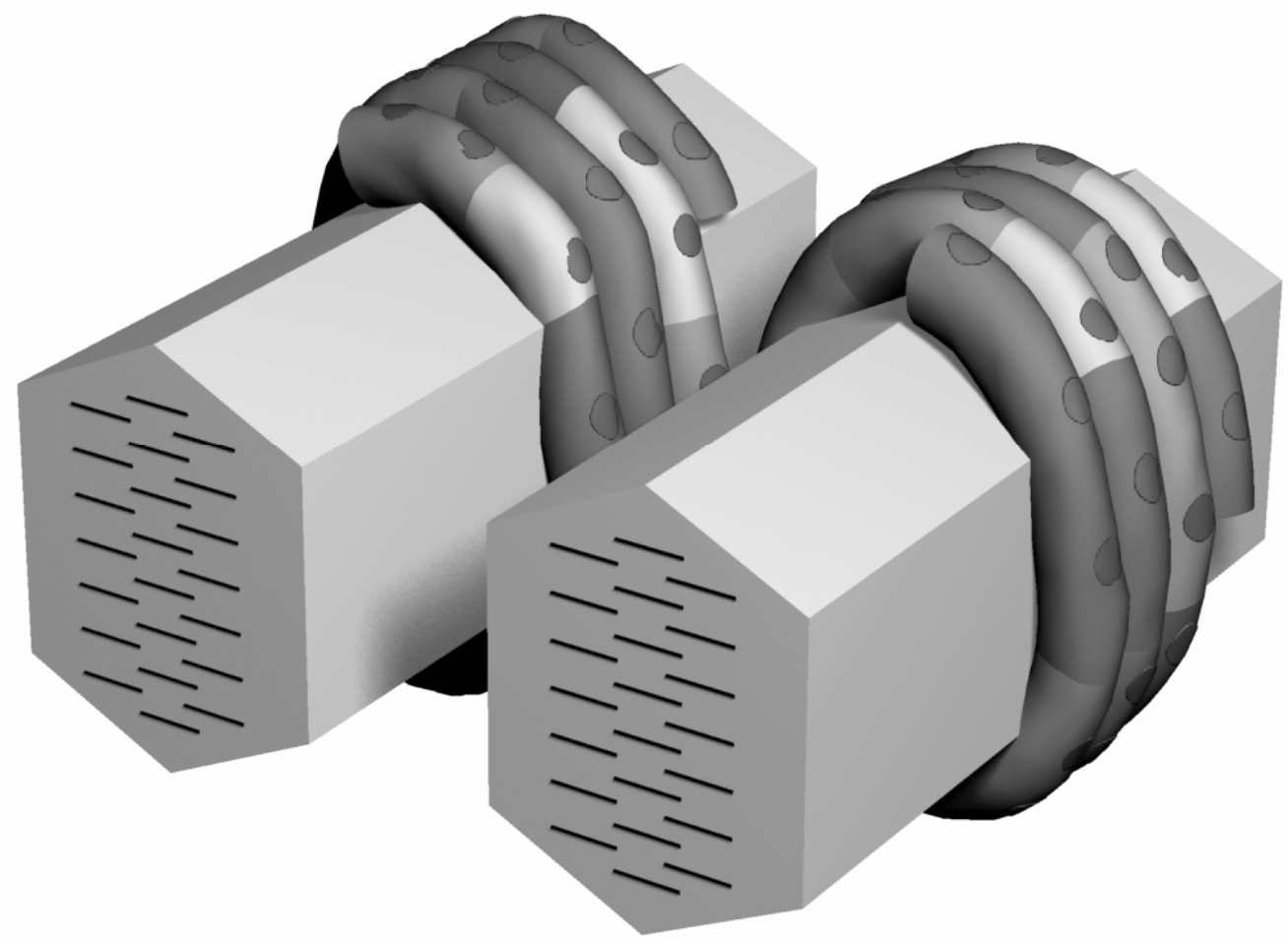

Figure 3. Model of chitin-molecules (black lines) organised in crystals (grey hexagon shape) wrapped in proteins (darker grey tube). Different grey colours represent different proteins. The crystals have an diameter of $2.8 \mathrm{~nm}$ an a length of several hundreds $\mathrm{nm}$. The figure is based on the descriptions by Raabe et al. Giraud-Guille and Vincent $^{[43,47,49,50]}$.

The theory that the formation of the cuticle is a process of self assembly gains strength by the fact that a) its structure in no way resembles the microvilli surface of the epidermal cells and therefore can not function as a template. b) the nanofibrils behave as cholesteric crystals forming layers with a twist of each successive layer. The nanofibrils might cluster further together in chitin-protein fibres which have a diameter of 50-300 $\mathrm{nm}$ as in crabs and crayfish and arranged in a 3 dimensional branched network ${ }^{[47,50,51,52]}$. c) In a laboratory test collagen self-assembles into cholesteric liquid crystals $^{[53,54]}$. d) In a laboratory test chitin self-assembles into nano-spheres ${ }^{[55]}$.

It has been suggested that the layers is a result from a continuous production - the so called WeisFogh screw carpet model. Several microvilli might be arranged in a super compartment with "a central rotational axis" ${ }^{[56]}$. The production of chitin crystals first assemble spontaneous into fibres $^{[18,36,57]}$ that then adhere to the underside of the epicuticle. As more fibres are produced they first form a continuous sheet that then turns into spirals with one or several arms and as one turn is filled up the production just continues sub ducted the earlier produced fibres ${ }^{[57,58,59]}$. However, these hypotheses have not been verified. 


\subsection{Empirical evidence is not without ambiguity}

Many of the micrographs of beetles and other arthropods show apparently separate layers within the exocuticle. The micrographs are found using various types of electron microscopy, especially Scanning Electron Microscopy (SEM) and Transmission Electron Microscopy (TEM). Both types are open for more interpretations and preparation and the microscopy itself can introduce changes to the substrate. Both techniques require a cross section of the substrate and a sample must therefore first be broken or cut. A fragile fracture can be made by cooling the sample in floating nitrogen and a microtome can provide both vertical and oblique cuts.

SEM requires a conductive surface which normally is achieved by coating with a thin layer of gold. This means that only the surface topology is seen and that different materials will look the same. The resolution means that details smaller than $10 \mathrm{~nm}$ are difficult to see.

TEM also applies a vacuum and the electron beam can affect the substrate. Transparent samples must be treated to reveal any structural elements before going into the microscope. The samples are normally treated with "electron dense dyes" which can adhere to the different structural elements e.g. different proteins. For transmission electron micrograph they are treated chemically and often stained $^{[13,60]}$.

Chitin is chemically very stable $\mathrm{e}^{[61]}$ and is therefore typically not receptive to the staining. It will appear white in the micrographs where individual chitin rods are seen. Stained protein appears dark. But when chitin is joined with proteins in a fibril mesh, it is dependent on the specific colouring agent binding to the mesh proteins, whether the chitinous layer appears white or black. A section stained with electron dense material e.g. osmium would be expected to bind to the structural proteins, and if the sample further is washed prior to micro photographing, only the structural mesh is seen as black. White areas could then be layers mostly consisting of water with some proteins. But the sample preparation and micro photographing could alter the microstructure of a sample e.g. water is known to evaporate during electron bombardment and the thickness of watery layers are insecure ${ }^{[29,60,61]}$. As the measured layer thicknesses on the micrographs are crucial for the interpretation of which colours could be reflected a natural question therefore is if we can be certain on the interpretation of the empirical evidence.

Some authors find that dimensions found in the TEM microscopies can only match the optical calculations if shrinkage of $10-15 \%$ is assumed ${ }^{[30,32]}$. This shrinkage is presumed to be caused by the preparation procedure and the electron beam. Schultz ${ }^{[25]}$ tested this hypothesis on tiger beetles of the genus Cincindela, but found no shrinkage. After preparation the samples showed unchanged structural colour and bi-layer thicknesses were similar in SEM and TEM microscopies.

Another source to uncertainty is the chemical identification of substances. Richards ${ }^{[62]}$ describes methods for detection and estimation of chitin. One conclusion is that a positive test result is fairly certain, but a negative result does not prove the absence of chitin.

\subsection{The cuticle materials}

The material in the beetle cuticle is often referred to as chitin, but the cuticle is more complex where the most abundant constituents are, water, proteins, chitin and sometimes crystals of calcium and uric acid ${ }^{[13,20,21,22,24,36,38,63,64]}$. 
Chitin recently has become a substance of much scientific investigation ${ }^{[65,66,67]}$. In the insect cuticle it has been compared to the rods of armoured concrete ${ }^{[44]}$. Chitin is a union of mono sugars with both an amine and a carbonyl group and bound together through covalent bonding. The sugar makes long strings and can have a molecular weight of between 30000 and 160000 dependent of how many "single" sugar units there are. In micro fibrils the individual chitin molecules are stabilized by hydrogen bonds between their side groups ${ }^{[43,44]}$.

Chitin is the second most common biological substance. It is found in invertebrates; in worms, arthropods, molluscs and in "lower" plants such as mushrooms, algae and lichens. The yearly production in the hydrosphere has been estimated to $1,361 \times 10^{9}$ ton $^{[68]}$. In insects chitin is not only found in the cuticle, but also in other surfaces that topologically is in contact with the outside world, e.g. the lining of the respiration system (the trachea) and of the digestive system (the peritrophic matrix) ${ }^{[23,69,70]}$.

The Proteins of the cuticle are very diverse and more than 100 different proteins are found ${ }^{[20,71,72]}$.

After formation of the fibril mesh work crystals of calcium or uric acid can be incorporated in the structure and change its physical properties ${ }^{[73]}$. In crabs and crayfish a substantial part of the cuticle is calcium crystals which give the structure enhanced stiffness ${ }^{[4,52]}$. In some of the scarabaeid beetles' uric acid is a part of the colour generating structure enhancing the reflectivity. In Plusiotis Optima and Plusiotis resplendens uric acid accounts for respectively 0.6 and 0.7 volume fraction of the exocuticle ${ }^{[12]}$.

\section{THE OPTICALLY INACTIVE MULTILAYER CUTICLE STRUCTURE}

One explanation of the colours and the reflections from beetles is that they result from interference from multiple thin layers ${ }^{[74]}$. Thin layers do not change the orientation of polarized light and is therefore referred to as optically inactive ${ }^{[13]}$. Multilayer structures require alternating layers with two different optical indices. This can be achieved either with two different materials or with a single material where the content of water or liquid is different in alternating layers.

The multiple thin layers can be seen in many of the transverse cuticle micrographs from beetles as separate dark and light layers located in the epicuticle and the exocuticle ${ }^{[6,11,13,17,25,26,29,30]}$. Similar layers are also found in other insects ${ }^{[13,42,60,61,75]}$. In the tiger beetle Cicindela campestris (green) and the buprestid beetle Chrysochroa vittata (red and green stripes) the colour generating sections are 1$2 \mu \mathrm{m}$ thick (Mossakowski 1979). In the tortoise beetle Aspidomorpha tecta (brass-golden) the thickness of the colour generating sections is about $9 \mu \mathrm{m}$.

\subsection{Thin layer interference}

The colours seen from reflection from thin layers are caused by interference ${ }^{[14,76,77]}$. The incident white light will interfere constructively in a thin film and cause that the spectrum of the reflected light will be different showing a peak for a certain wavelength matching the film material and thickness. The angle of incident light determines the path a ray travels through a thin film or a multiple layer stack. Therefore interference colours are angle sensitive and thin layer interference is said to exhibit a blue shift where shorter wavelengths are reflected for grazing incidence as shown in figure 1B. 
Maximum reflectivity is achieved in a so-called ideal multilayer stack where pairs of thin layers of 2 materials $\mathrm{a}$ and $\mathrm{b}$ are placed on top of each other. In an ideal multilayer stack the optical thickness for each layer is equal to a $1 / 4$ wavelength and therefore $d_{a} n_{a}=d_{b} n_{b}$ where $d_{a}$ and $d_{b}$ are the layer thicknesses and $n_{a}$ and $n_{b}$ the refractive indices. If the stack is placed on a substrate of higher refractive index the reflected colour can be estimated from

$2\left(d_{a} n_{a} \cos \theta_{a}+d_{b} n_{b} \cos \theta_{b}\right)=h \lambda$,

where $\theta_{a}$ and $\theta_{b}$ the angle from normal, $h$ an integer and $\lambda$ the wavelength of the reflected light $^{[14,76,77]}$.

For normal incidence in an ideal multilayer stack the formula can be expressed as

$4 d_{a} n_{a}=h \lambda$

This indicates that layer thickness for the ideal multilayer stacks is in the range of $60-120 \mathrm{~nm}$ for chitin materials with a refractive index around 1.5. For higher refractive index the layer thickness can be smaller, e.g. for $n=2.0$ the thickness range is as low as $50-90 \mathrm{~nm}$. For non-ideal multilayer stacks the layer thickness can be different from this, but reflectivity will be lower.

2 different methods are used to calculate the reflectivity from multilayer structures. The first method is described by ${ }^{[76,77,78,79]}$ and is emphasized for its simpler mathematics. It is however restricted to stacks consisting of regularly repeated sequence of layers.

For an ideal multilayer stack the reflectivity can be estimated from the formula below. The reflectivity is the ratio between the reflected and the incident light intensity. $n_{a}$ and $n_{b}$ are the refractive indices for the 2 different types of layers in the stack and $p$ the number of double layers. For other wavelengths than the ideal the reflectivity is smaller.

$$
R^{2}=\left[\frac{1-\left(\frac{n_{a}}{n_{b}}\right)^{2 p}}{1+\left(\frac{n_{a}}{n_{b}}\right)^{2 p}}\right]^{2}
$$

When the 2 refractive indices are similar in size a larger number of layers are required in order to achieve high reflectivity. For example is 60 pairs of layers required to get about $90 \%$ reflectivity when $n_{a}=1,5$ and $n_{b}=1,6$. If the difference between the two refractive indices are larger only fewer layers a required. $90 \%$ reflectivity can be reached when $n_{a}=1,5$ and $n_{b}=2,0$ for only 13 pair of layers.

The other method called the transfer matrix method is described by ${ }^{[80,81]}$. Steinbrecht et.al ${ }^{[61]}$ use the matrix method to calculate the reflectivity from a multilayer stack for normally incident light. They further compare the calculated reflectivity with the measured reflectivity of a number of beetle species. Three of the conclusions drawn are: 1) a stack with equal thick layers gives narrow band reflection, whereas a stack with changing layer thickness (also called chirped) gives a more broad band reflection, 2) the calculated reflectivity gives a much more "noisy" curve than the measured 3) 
the total calculated reflectivity is higher than the measured. The natural multi layer structures have irregularities which are known to scatter and absorb part of the light. In the computed spectra, reflectance reaches $100 \%$ for wavelengths larger than $550 \mathrm{~nm}$, while it only reaches between 70 $90 \%$ in measured spectral curve.

Vigneron et al. ${ }^{[28]}$ describes a simplified method for determining the dominant wavelength for a multilayer reflector with 2 alternating different layers. The method assumes an infinite multilayer stack and a little refractive index contrast. $\lambda$ is the wavelength, $a$ is the thickness of the 2 different layers $l_{1}+l_{2}, \bar{n}$ is the average refractive index, $\theta$ is the angle from normal and $\mathrm{m}$ is an integer.

$\lambda=\frac{2 a \sqrt{n^{2}-\sin ^{2} \theta}}{m}$, for normal incidence $: \lambda=\frac{2 a \bar{n}}{m}$

The method confirms the empirical experience that thicker layers result in longer reflected wavelengths. It furthermore shows that a typical layer thickness (a) for visual colours is in the order of $100-200 \mathrm{~nm}$, all though also thinner layers are possible.

In connection with interference phenomena several authors have shown pictures of cuticle sections with seemingly clearly separated layers ${ }^{[11,13,28,29,32,61,77]}$. By assigning different optical indices to these layers it is possible to calculate bandwidth and colour shifts.

Figure 4 is a TEM-picture ${ }^{[35]}$ that shows a vertical cut of the golden beetle Aspidomorpha tecta. The black "lines" are the fixed protein-chitin rich layers - sometimes called D-layers for dense - and the white "lines" are water rich layers - referred to as C-layers for clear ${ }^{[61]}$. The thickness of the D layers is almost constant, whereas the $\mathrm{C}$ layers gradually gets thinner inward. The outermost $\mathrm{C}$ and $\mathrm{D}$ layer pairs are formed at first and therefore it is reasonable that long waves are the ones first reflected as the beetle cuticle develops. The beetle should start as red and then become more orange, yellow and brighter as more short wavelength layers develop. 


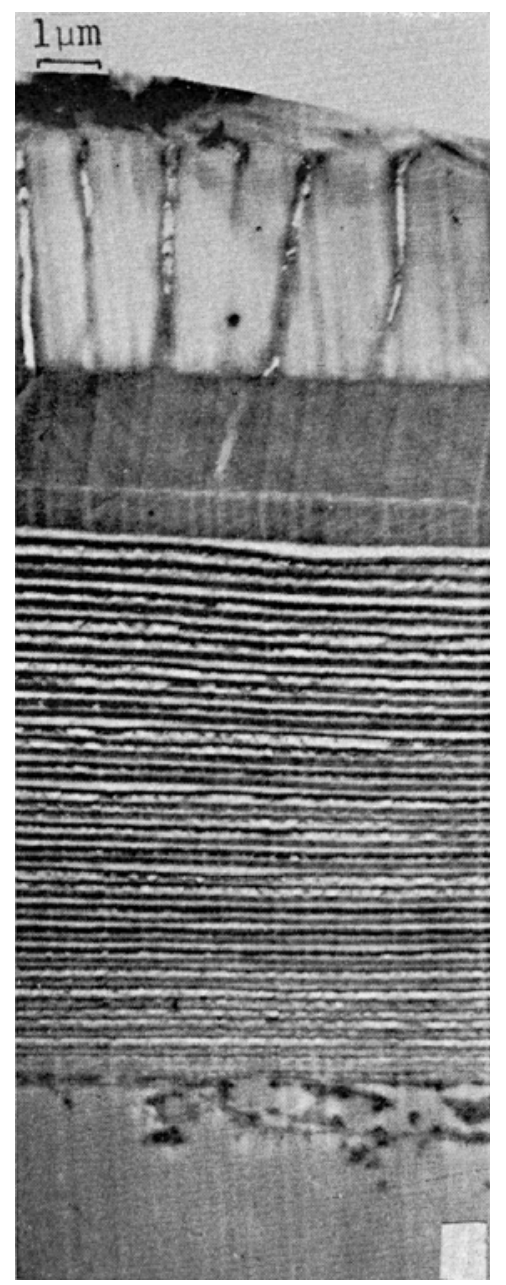

Figure 4. Electron micrograph by Hinton 1973 of a vertical cut through the cuticle of Aspidomorpha tecta with gold appearance. With kind permission from British Journal of Entomology Proceedings.

According to Neville ${ }^{[11]}$ Aspidomorpha tecta turns yellow before any metallic colours appear 3 to 4 days after the final ecdysis. If the live beetle is provoked some of its surface changes colour from gold to red in about two minutes. Such a change can also be achieved by soaking pieces of dead cuticle in $\mathrm{pH}$ buffered solutions. As proteins often change charge with change in $\mathrm{pH}$, it is likely that some of the proteins' ability to bind water in Aspidomorpha tecta is affected. An uptake of more water makes the distance between the layers larger and thus result in a colour change towards the long red waves. As the $\mathrm{pH}$ change must be induced by the living cells at the bottom of the stack, it is reasonable to presume that the lower layers are more perceptible or at least first reacting.

There is a big difference in the constituents of multi layered stacks in beetles. It is known that some loses their colours when they die and dry up ${ }^{[82]}$. Some will regain their colours if the cuticle is wetted $^{[11,83]}$. Others keep their colours after death. The difference can be explained based on where the colour generating structure is placed. If it is part of the epicuticle or the exocuticle, colours remain after death, since the structure is fixed. If the structure is part of the endocuticle, colours are lost after death. The reason is that the endocuticle is not hardened, and has a higher water content which is lost when the insect dies.

Neville ${ }^{[48]}$ has shown that the protein-chitin fibres in locust exocuticle are structured differently during the day and night cycle. In the daytime all the layers have fibres oriented in the same 
direction while in the night time they form socalled Bouligand structures (see later). Professor in biochemistry S.O. Andersen ${ }^{[84]}$ believes that this can be caused by the production of different proteins in the day and night cycle.

\subsection{Optical parameters}

Figure 5 shows a layered structure in the green shell of the beetle Heterorrhina elegans ${ }^{[13]}$. An interpretation of figure 5 could be that we have a multi-layer reflector, where the white areas are the watery layers (C) and the black areas the chitinous or dense layers (D). All D and C layers are even in thickness and this should give a narrow band reflector. Assuming that the reflector is an ideal multilayer and the reflected light in the normal direction is measured to $570 \mathrm{~nm}$ refractive indices can be calculated to 1,75 and 1,38. Even though these indices are possible they are different from what one would expect. It seems likely that the reflector is not an ideal stack.

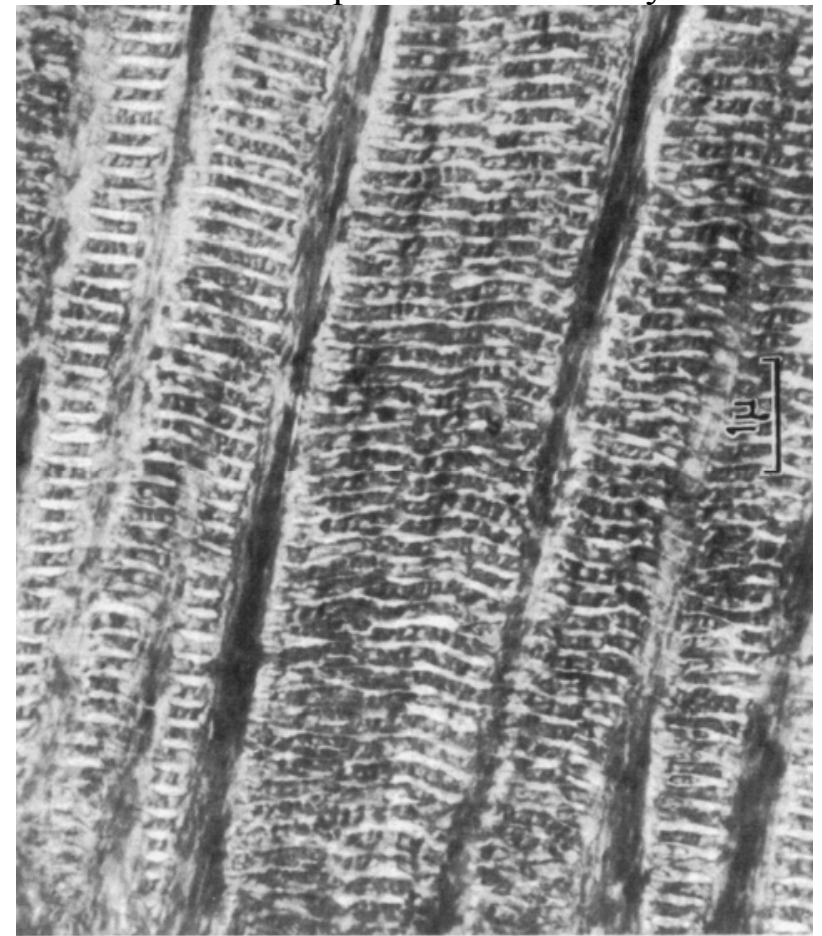

Figure 5. Electron micrograph of a section cut vertically through the optically inactive layers in the elytron (cover wing) of Heterorrhina elegans (beetle) ${ }^{[13]}$. The cuticle reflects green colours. With kind permission of Springer Science and Business Media. 
Typical refractive indices for beetle cuticle seem to be around 1,56. Layers with water or air content could be lower and if tanning or other materials are present a higher refractive index can be found. Land $^{[77]}$ makes optical calculations on different layered structures. For fish scales he uses a refractive index $n=1,83$ for guanin and $n=1,33$ for water. For insects $n=1,56$ for chitin and $n=1,0$ for air is used. Steinbrecht et al. ${ }^{[61]}$ has measured the optical properties for golden and silver butterfly pupae (Euploea core and Amauris ochlea) and found over 70\% reflectivity for light from 550 to 800 $\mathrm{nm}$. There are up to 250 layers. The refractive indices where measured to 1,58 and 1,37. The high index layers have a constant thickness while the low index layers vary in thickness with the thickest layers in the middle. When thin sections of the cuticle are peeled of the resulting colour is changed towards shorter wavelengths. Vukusic et al. ${ }^{[42]}$ reports findings from the bright green dorsal iridescence of the hindwings of Neurobasis chinensis chinensis males (a damselfly). A laminar structure is responsible and 3 refractive indices are found: 1,47, 1,68 and 1,74.

Vigneron et al. describe the study of a Chrysochroa vittata ${ }^{[28]}$ and Hoplia coerulea ${ }^{[84]}$. Based on SEM-pictures of Chrysochroa vittata they conclude that the optical reflector probably is a multilayer reflector with 20 layers. Their hypothesis is that layers of chitin with a thickness of about $200 \mathrm{~nm}$ alternate with very thin layers $(10 \mathrm{~nm})$ of air. It is however not possible to verify the air layer using SEM. An artificial multilayer structure was made based on the findings using $\mathrm{SiO}$ and Nickel. It reflects similar colours as the beetle. Structures with alternating layers of air and chitin are known from butterflies. However, here the colour generating structures are not internal but a result of a folding of the surface of their scales ("sculpted multilayers") ${ }^{[6,86,87]}$.

\section{THE OPTICALLY ACTIVE BOULIGAND CUTICLE STRUCTURES}

Another architecture that can explain the colours and the reflections from beetles is the helical socalled Bouligand structures ${ }^{[88]}$. These structures change the orientation of polarization and are therefore referred to as optically active ${ }^{[13]}$. 


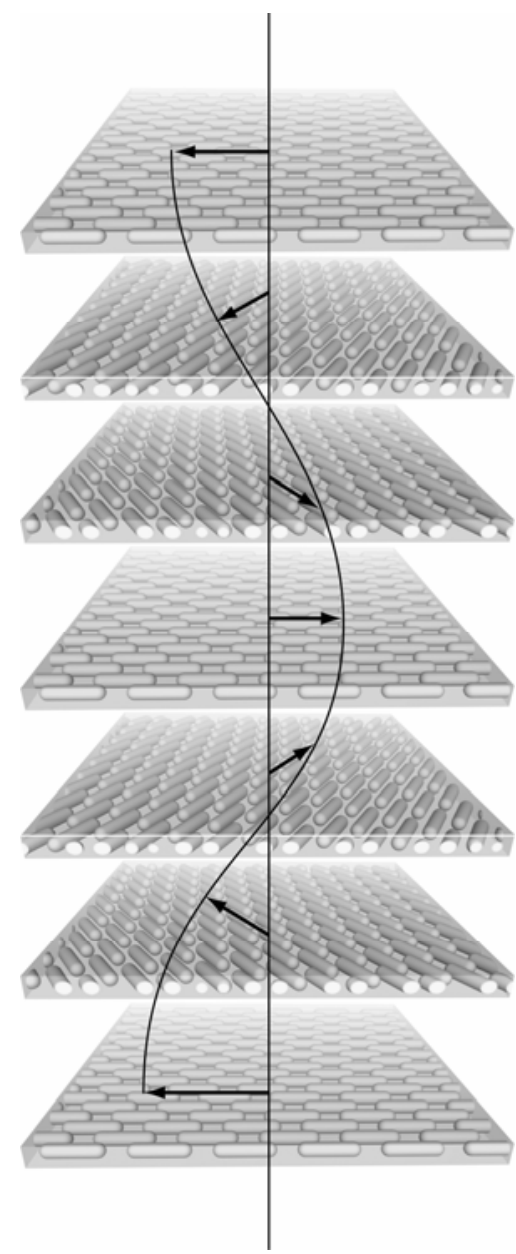

Figure 6. Three-dimensional model of the cholesteric organization. Superimposed cards represent equidistant and parallel planes. On each card the molecular orientations of fibres are represented as parallel lines, their direction rotating by a small and constant angle from one plane to the other. $\mathrm{A} 180^{\circ}$ rotation of the molecular directions defines the half helicoidal pitch $(\mathbf{P} / 2)$.

Bouligand structures have the same general arrangement as cholesteric liquid crystals as shown in figure 6. The layers are formed by long threadlike chiral molecules. Within each layer all threads lie parallel, but because of the chirality the layers have a twist to each other with regard to thread orientation (director). A total rotation of the director of the layers through $360^{0}$ is called the pitch $^{[89]}$. The term cholesteric now refers to this kind of structures because it was first found in connection with cholesteryl derivates ${ }^{[32]}$. It is also called a helicoidal structure ${ }^{[32,48]}$.

From a biomimetic point of view the Bouligand structures are interesting since each layer in the stack is made from the same material. The threads in the layers are birefringent. Hodgkinson et. al. ${ }^{[90]}$ describes an optical model for the reflection from the manuka beetle Pyronota festiva. Here the refractive index in the direction of the thread is higher than in directions perpendicular to this. The structure reflects circular polarized light of the same handedness as the helicoid and transmits circular polarized light with the opposite handedness.

Circular polarized light is a helical 3-d wave that can be modelled as two plane polarized waves perpendicular to each other on the same trajectory. It is circular when the two planes are $1 / 4$ wavelength out of phase. A right circular polarized wave turns into a left, when one of the two 
planes is pushed $1 / 2$ wavelength. When two circular polarized waves with opposite rotation follow the same trajectory, they turn into a plane polarized wave ${ }^{[91]}$.

By convention the helical twist of light and structures are named different. A left circular twist in a structure like a beetle cuticle means that successive layers seen from the surface rotate counter clockwise. Light following the same counter clockwise path down through the structure is called right circular polarized ${ }^{[48,91,92]}$. When white light is incident on a surface of a left helicoidal Bouligand structure (parallel to the twist) selective reflection takes place and only left circular polarized light is reflected, whereas right circular light is transmitted ${ }^{[12,13]}$. Moreover, contrary to usual experience, the reflected wave has the same sense of circular polarization as that of the incident wave (in opposition to a circular polarized wave reflected in a mirror) ${ }^{[93]}$. Most beetles and other arthropods have a left circular structure ${ }^{[48]}$.

\subsection{Arched patterns}

In the beginning of the last century a number of scientists compared the colour generating mechanisms of beetles and cholesteric liquids crystals and found them to be similar. In 1924 Gaubert compared the optical properties of adult beetles in the family Scarabidae with cholesteric liquid crystals ${ }^{[32]}$, but the $3-d$ structure of the beetle cuticle could not be resolved. When electron micrographs emerged the picture became more confused as most pictures of the beetle cuticle showed a complicated mesh of arcs. However, that the arced patterns typically observed in cells and tissues of biological systems, did not result from authentic curved filaments, but originated from the successive molecular orientations found in layers is credited to Bouligand (figure $7{ }^{[54]}$. This is also called twisted plywood arrangements ${ }^{[49]}$.
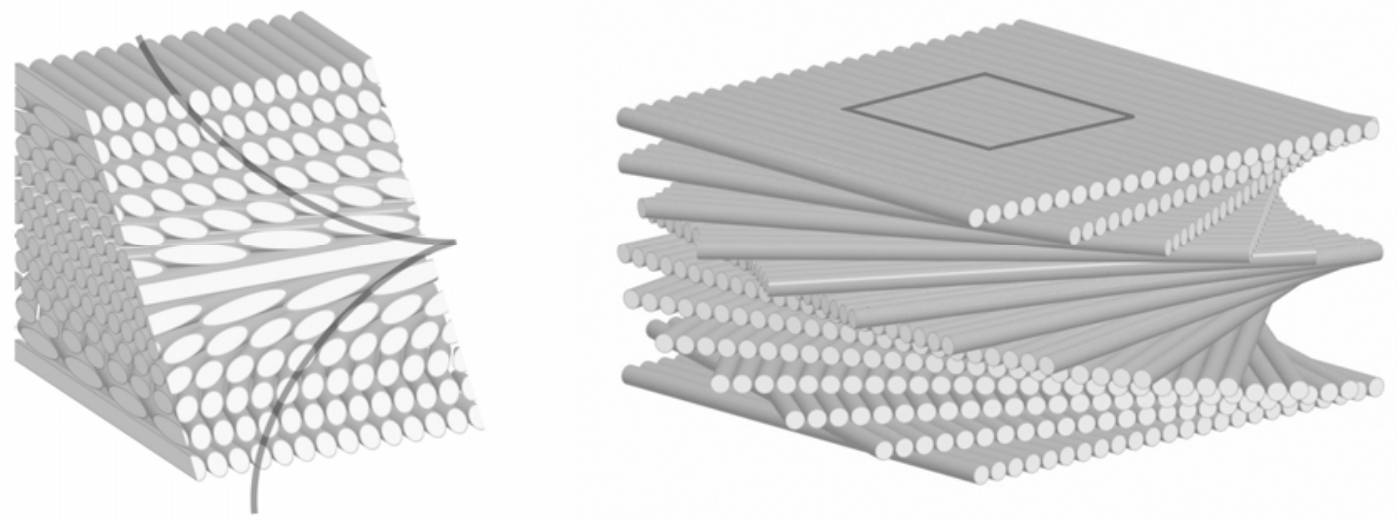

Figure 7. Model illustrating helical Bouligand structure. The left picture illustrates the arcs seen in micrographs of oblique cut sections. The dark square in the picture at right shows where the cut out is made.

Helicoidal structures are found in a lot of natural structures. Figure 8 shows a structure from a grasshopper. The super arrangement of molecules gives optical properties totally different from those of the individual constituent molecules namely selective reflection of circularly polarized light and a rotary power about a thousand times greater than that of an ordinary optically active substance ${ }^{[93]}$. The rotary power is a measure of how much the analyser has to be twisted to extinguish light when a sample with a given thickness is placed between crossed polars. The rotary power is used as a standard measure in both chemistry and geology. 


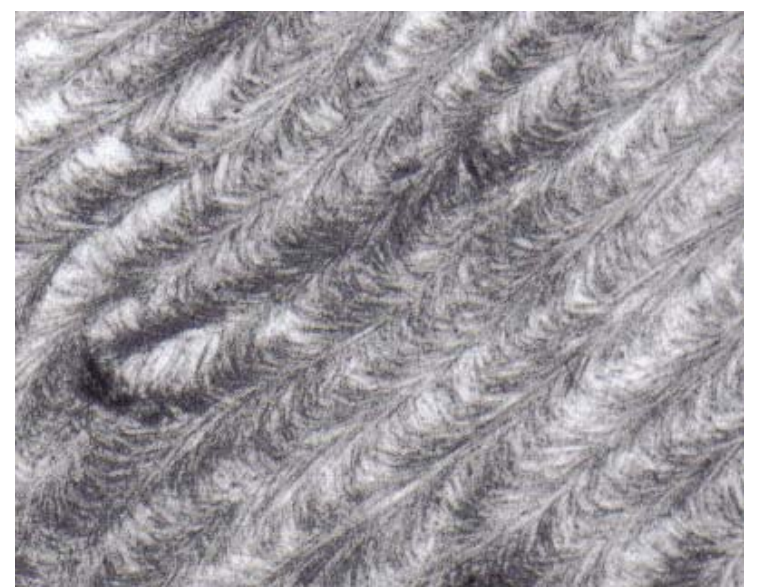

Figure 8. Electron micrograph of inner shield layers in a grasshopper illustrating the arcs from the bouligand structure. Kindly provided by Prof. Svend Olav Andersen, Copenhagen University.

The discovery of liquid crystals is attributed to Reinitzer who in 1888 noted that cholesteryl benzoate exhibits an unusual type of melting phenomenon: at $145,5^{\circ} \mathrm{C}$ the solid melts into a cloudy liquid which, on further heating, suddenly becomes clear at $178,5{ }^{\circ} \mathrm{C}$. There are now several thousands of organic compounds known to form liquid crystals and there is a large interest in this field due to the connection with display technology ${ }^{[93]}$.

Bouligand stressed that the direct relationship between the cholesterics and the Bouligand structure strongly suggest that biological macro-molecules with this organization first go through a stage as liquid crystals ${ }^{[59,88]}$. The major component of a lot of nanoscale super structures seen in the nature can be described as long threadlike molecules e.g. cellulose, chitin and collagen ${ }^{[49]}$. Recent advances in the understanding of the molecular structure and that Bouligand structures are found in some arthropod cuticles ${ }^{[11,52]}$, fish scales ${ }^{[94,95,96]}$, bones ${ }^{[97,98,99]}$, wooden structures ${ }^{[100]}$, bacterial cell walls $^{[101]}$ and liquid crystals ${ }^{[93,102,103,104,105]}$ points towards that there is a general principle governing the formation of all these structures. Super structures formed by an assembly of nanoscale chiral threads in fluids often behave in similar fashion with respect to light regardless their chemical composition.

\subsection{Self-assembly}

It has been demonstrated that three-dimensional fibril assemblies implies a liquid crystalline ordering of molecules prior to organization of crystals into microfibres and fibres. Belamie et al. ${ }^{[33]}$ and Giraud-Guille et al. ${ }^{[54]}$ demonstrate that laboratory suspensions of collagen actually can selfassemble into a Bouligand structure, going through an isotrophic phase and a cholesteric phase. In the last phase individual molecules also assemble into fibrils ${ }^{[54,106,107]}$. When collagen molecules artificially are mixed into solutions they can achieve a progressive spontaneous order. Successive geometrical arrangements, due to molecular alignment, undulation and twist, are reached as long as the liquid crystalline state (thus the ability of molecules to move one next to the other) is maintained. Samples appear at first isotropic, with molecules in a disordered state. This results in total extinctions of light when a sample is placed between crossed polars. A new phase then appears due to the parallel alignment of monomers (nematic order), inducing a uniform birefringence. As the concentration increases, by solvent evaporation, precholesteric textures transform into fingerprint patterns typical of cholesteric liquid chrystals ${ }^{[54]}$. In a laboratory test ${ }^{[55]}$ it is demonstrated that when chitin or chitosan from crab shell waste where allowed to form a colloidal 
suspension and their electrostatic characteristics where manipulated altering the $\mathrm{pH}$ small spheres could form. These form by self assembly and could have a cholesteric liquid crystalline structure. The method of manipulating the $\mathrm{pH}$ could be a kind of "remote control" method used by arthropods in the formation of helicoids in the cuticle.

The arrangements of "long chiral molecules" in cholesteric liquid crystals and the Bouligand structure is the same. Cholesteric liquid crystals are characterized by absence of positional order and by long range orientational order of the long molecular axes ${ }^{[93]}$. However in the Bouligand structure, the freedom of the individual molecules is restricted. In arthropods the constituents of the cuticle changes constitution due to the processes of sclerotization and tanning, which used for arthropods, refer to the processes by which the cuticler structure is made stiffer, less soluble, more resistant to degradation, and often darker. The generally accepted theory is that cuticler proteins are cross-linked by reaction with quinines ${ }^{[38]}$ and catechols ${ }^{[108]}$.

\subsection{Reflection in a helicoidal structure}

When white light is incident on a surface of a helicoidal structure (parallel to the twist) selective reflection takes place. The wavelengths of the reflected maxima are varying with the angle of incidence in relation to the crystal plane (not in relation to the normal of the plane) in accordance with Bragg's law ${ }^{[32]}$ :

$\lambda=2 \operatorname{Sn} \sin (v)$,

where $\lambda$ is the wavelength of colour, observed at an angle $\mathrm{v}$ to the surface in a system of planes of refractive index $\mathrm{n}$. S is the distance between planes where the threads are parallel or in other words half a pitch. The largest reflectivity for a given colour is obtained when the optical thickness of a half pitch is equal to the wavelength of the colour. Thus the Bouligand system also is referred to as a $1 / 2$ wave interference system ${ }^{[89]}$. In a layered structure with many pitches each pitch gives the reflection of one wavelength. The intensity of a given colour increases with the number of pitches reflecting the wavelength of the colour ${ }^{[82,90]}$. Some beetles e. g. tiger beetles have different stacks of pitches all over their cuticle resulting in pointillistic mix of colours ${ }^{[6,90,109]}$. 


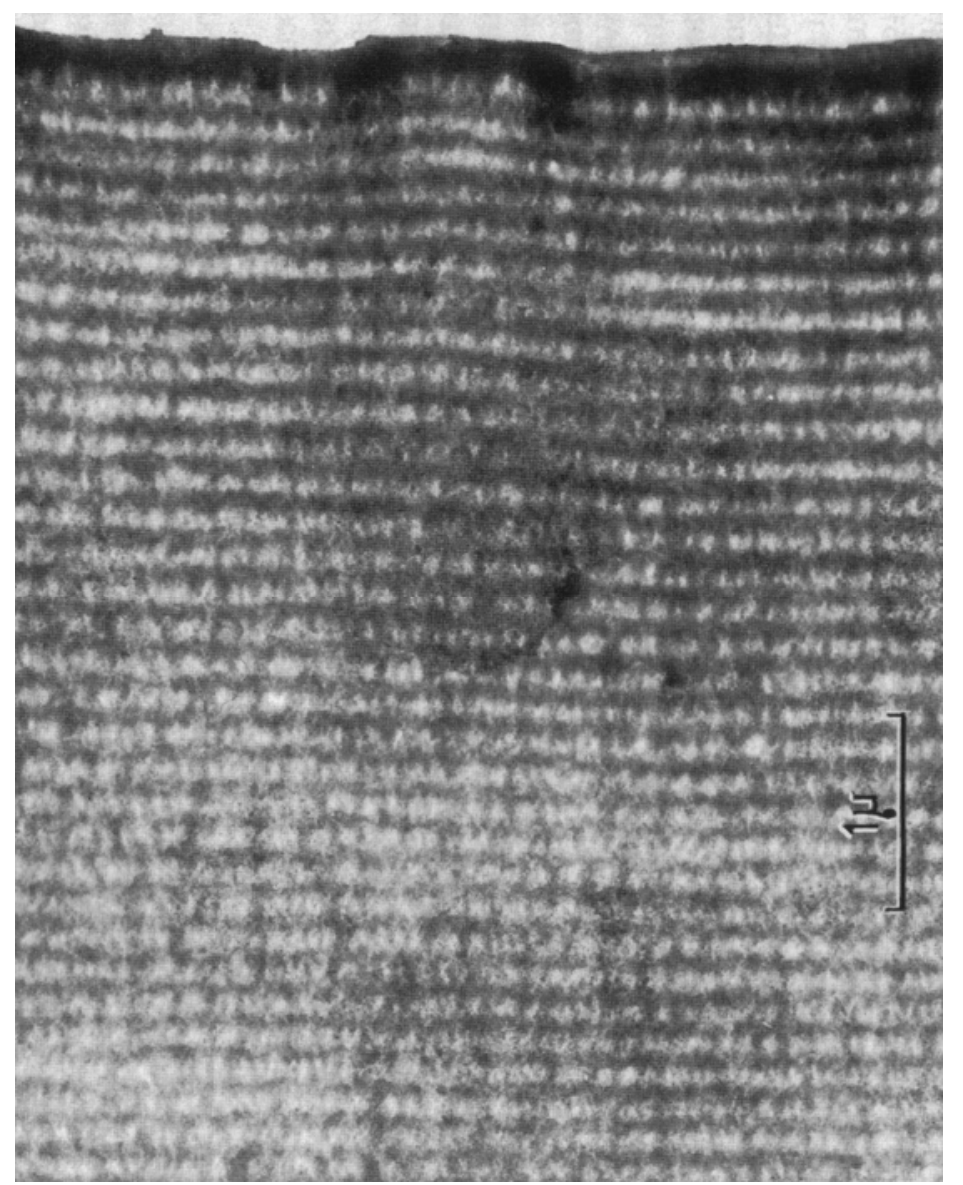

Figure 9. Micrograph of a vertical cut through the optically active layers in the elytra of Potosia Speciosissima resulting in green to bronze interference colours ${ }^{[13]}$. With kind permission of Springer Science and Business Media.

Figure 9 shows a micrograf of a vertical cut through the optically active helicoidal layers in the elytra of Potosia Speciosissima that exhibits green to bronze interference colours ${ }^{[13]}$. The distance between white (or black) stripes increases a little from the top to the bottom of the micrograph from app. 165 to $200 \mathrm{~nm}$. With a refractive index of $\mathrm{n}=1.525$ this corresponds to optical paths and colours of respectively $505 \mathrm{~nm}$ (bluegreen) and $610 \mathrm{~nm}$ (orangered). Thus with more than 30 halftwists this should give a metallic sheen with an intermedient hue of the previous mentioned colours. Polishing the beetle cuticle has long been used to identify the position of specific colour reflecting layers e.g. Lord Rayleight ${ }^{[74]}$. A polishing experiment of the shown beetle cuticle changed the colour appearance from bronze to yellow to red. When tilting the samples unpolished bronze went deep green and red polished areas went yellow to apple green.

For a beetle with a helicoidal structure the colours change towards shorter wavelengths (i.e. the yellow becomes green, green becomes blue etc.) as the angle of viewing is increased relative to a direction normal to the whole cuticle surface ${ }^{[90]}$.

When viewed between crossed polaroids from any direction perpendicular to the axis of rotation, there will be retardation maxima altering with retardation minima for every $180^{0}$ rotation $^{[89]}$. The system will give the appearance of lamella, with two lamellae per $360{ }^{0}$ rotation of plane of anisometric units: a complete rotation of $360^{\circ}$ is the pitch of the system. 


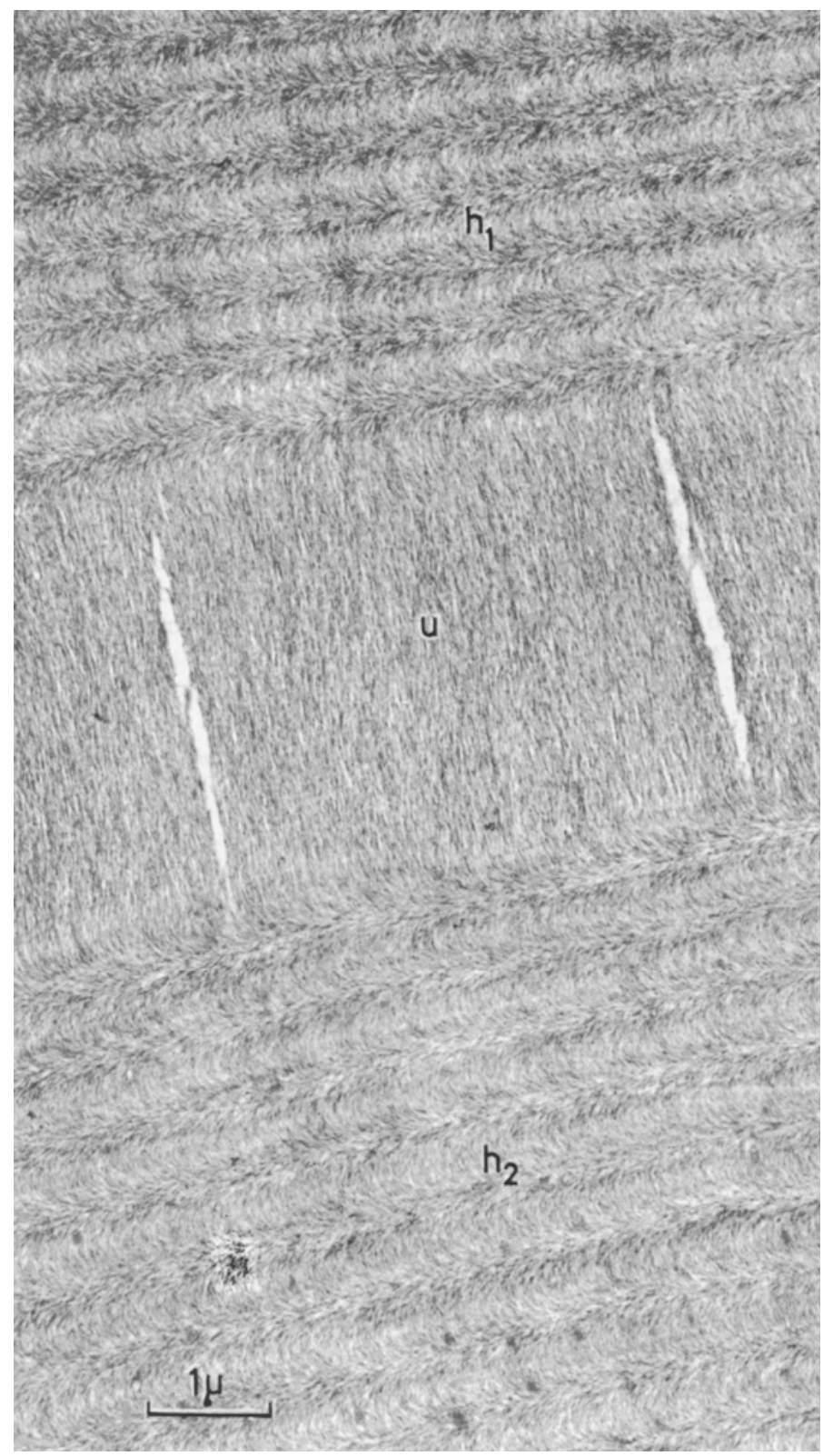

Figure 10. Electron micrograph of an oblique section cut through the optically active reflecting layer in the outer exocuticle of Plusiotis resplendens ${ }^{[12]}$. With kind permission of The Royal Society of London.

Insects have Bouligand structures in general. Among beetles the Scarabaidae are known to have these in the outer light reflecting layers resulting in interference colours of left circular polarized light. However Plusiotis resplendens (shown in figure 1A) is remarkable since it reflects both left and right circular polarized light. Figure 10 shows an electron micrograph by Neville and Caveney ${ }^{[12,13]}$ of an oblique cut through the optically active reflecting layer in the outer exocuticle of Plusiotis resplendens. The phenomena is explained in the following way. A layer of unidirectional oriented chitin crystalites $(\mathrm{u})$ is sandwiched beteen two helicoidal layers $(\mathrm{h} 1, \mathrm{~h} 2)$. The thickness of the whole optical layer is measured to $22 \mu \mathrm{m}$. Left circular polarized light (LCP) is reflected from the h1 layers, whereas right circular polarized light (RCP) goes through h1, is retarded about half a wavelength through $\mathrm{u}$ which turns it left circular. This then gets reflected in $\mathrm{h} 2$ changed again through $\mathrm{u}$ to RCP an transmitted through $\mathrm{h} 1$ to the surface. The whole construction thus reflects both LCP and RCP. 


\section{EXISTING AND BIOMIMETIC APPLICATIONS}

In this chapter we describe a number of structural colour applications similar to those found in nature. We furthermore look at what can be learned from the colouring mechanisms in beetles and their production in order to mimic this in man made materials and products. Our focus is primarily on aesthetic surfaces which can be mass produced at low cost.

\subsection{Existing structural colour applications}

Single layer interference surfaces are found a number of places. Kikuti et. al. ${ }^{[110]}$ describe three different chemical and electrochemical surface treatments of stainless steel resulting in single layer metal-oxide films with interference colours. Layer thickness was measured to between 70 and 400 $\mathrm{nm}$. Colours span most of the spectrum depending on the coating thickness. Apart from the colouring effect does the treatment for thin coatings improve the pitting corrosion resistance.

Similar oxide films can be seen in Japanese coloured stainless steel cutlery ${ }^{[111]}$ and in stainless steel facade elements ${ }^{[12]}$. The phenomena is also seen - unwanted - on stainless steel cooking equipment caused by oxidation from the gas-fire The advantage of these surfaces is that they are hard and lasting - the thin oxide film do not fade. Among disadvantages is their sensitivity to other coatings, which can change their optical properties. For example do fingerprints change the reflected colour.

Cathell ${ }^{[113]}$ describes how colour-based metal detectors can be made using very thin layers of alginate biopolymer. Alginate can be produced from algea and are applied to silicon wafers using spincoating. The thin layer of alginate is made water-stable using cross linking with calcium. The wafers have a distinct structural colour that changes when exposed to different metal-ions.

Weber et al. ${ }^{[14]}$ describes the development of multilayer polymer films that function as high reflective mirrors. The films are commercially avaliable and can be used for piping visible light over large distances as well as a number of other applications. The mirrors can be made largely insensitive to polarization effects by controlling where the Brewster angle appears. They are made from a large number of layers of PMMA and birefringent polyester.

Iohara et. al. ${ }^{[14,115]}$ describes a textile inspired by a Morpho butterfly. The textile filaments are made of polyester and have a flattened shape of thickness $15-17 \mu \mathrm{m}$, in which 61 layers of polyamide and polyester with a thickness of 70-90 $\mathrm{nm}$ are incorporated. The reflector stack is covered with a thicker coating of polyester. The reflectors can be aligned in the textile due to the flat shape of the filament resulting in better reflectivity. The textile reflects a single metallic colour that changes depending on the viewing angle. Colours from red to blue can be obtained by adjusting the layer thickness. Applications considered are textiles for apparel, curtains, car-cloth and short-cut fibres for car-paint.

Srinivasarao ${ }^{[92]}$ describes how they produced a cholesteric liquid crystal material similar to the beetle structure. This was done by mixing a commercial nematic liquid crystal with a chiral dopant. By changing the amount of dopant the pitch of the helicoidal structure could be controlled and hence the colour of the reflected light. The purpose was to convey optical measurements on reflectance spectra on structures similar to those found in beetles. 
Heinlein \& $\operatorname{Kasch}^{[116]}$ describes a commercial available paint pigment that has similar optical properties as a rose beetle. The pigment has a pronounced angular dependence, and the resulting paint will therefore have a different colour, e.g. change from red to green, depending on the viewing angle. The pigments are small platelets made from organosilicone material and are typically about $35 \mu \mathrm{m}$ wide. The material is a nematic liquid crystal doped with a chiral agent resulting in a helicoidal layered structure. The pigments are transparent and the resulting colours are interference colours. The pigments must be applied to a dark light absorbing background for the colour change effect to be distinct.

\subsection{Biomimetic applications}

Biomimetic design can either directly copy a design principle found in nature or it can develop new design principles with inspiration from nature ${ }^{[117]}$. A well known example of the former is the development of the Velcro fastener. When developing aesthetic pleasing surfaces it is more likely that the designs are more loosely inspired by the natural origin, and do not stick to the exact same structures and basic materials. An example is the beetle like surfaces made by Vigneron et al. ${ }^{[28]}$ using $\mathrm{SiO}$ and Nikkel for the alternating layers instead of chitinous ingrediens.

Seen from the industral designer's and the material designer's point of view there are a number of important findings in the study of optical phenomena in beetles. The most obvious is the diversity of colours and visual effects that can be produced by the beetles as illustrated in figure 1C. This includes the colour itself which can be narrow band or broadband contributing to differences in the perceived colour. The directionality of the reflection determines whether the surface is perceived as metallic or more diffuse. Angle dependency and colour change also varies a lot. The interference colours are sometimes combined with pigments and with different colour backgrounds. Al in al is a study of the diversity of the visual effects a valuable source for inspiration to new visual appearances in man made products.

More specifically are beetle shells a valuable inspiration for the technical design of the reflectors, i.e. the number and thickness of layers and their organisation. Similar inspiration can be found for pitch variations and number of spirals in helicoidal Bouligand structures. The natural reflectors also give insight into concrete materials and material combinations and the following refractive indices. Another very important issue is the control of iridescence. Nature shows us that it is possible to tune the iridescence from constant colour to all degrees of gradually or sudden angle dependent colour change. These phenomena are often achieved through varying types of irregularities. Beetle shells also serves as inspiration for how to control polarization and thereby combinations of transparency reflectivity.

Apart from an understanding the material structure itself are beetle shells a source for insight into possible techniques for manufacturing the structures. The combination of self-assembly and control which makes both the production of multilayer and Bouligand structures possible is difficult to study but never the less a valuable information source. 


\section{CONCLUSION}

Beetles in nature have several properties that are desired in industrial products: They have appealing brilliant colours and some look like made of metal. Colours and metal look comes from surfaces with 3-dimensional duple curvature. The colours are very long lasting - they can last several hundred years. Furthermore are beetles made from renewable materials that can be broken down and recycled when the beetle dies. Beetles also possess another very attractive property: Their metallic look originates from structures in organic materials which are both electrically and thermal insulating.

The spectacular colours and metallic sheen seen in beetles are well described in the literature. They originate from the internal micro- and nanostructure of the cuticle. The cuticle of the living beetles is a complex with hundreds of components, but the major and fibrous structural components of the cuticle form rather simple superstructures. Further it seems that the same superstructures can be reached rather independent of the exact chemical composition of the ingredients. This paper has examined two of the structures, namely, a layered structure and a helicoidal Bouligand structure which both can explain the emerging structural colours. The two identified structures are both relevant for further work in making artificial cuticle like surfaces with similar optical properties.

The multilayer structures require alternating layers with at least two different optical indices. This can be made with two different materials or with a single material where the content of water or liquid is different in alternating layers. Maximal reflectivity is achieved when both type of layers form a $1 / 4$-wavelength stack where the distance between identical layers are $1 / 4$ optical thickness, i.e. the physical distance multiplied with the refractive index. Typically the refractive index range between 1,5 and 1,7 and this corresponds to an optimal layer thicknesses for the visible spectrum between $60 \mathrm{~nm}$ and $120 \mathrm{~nm}$.

Helicoidal Bouligand structures do only require a single material shaped as nano-sized threads that are formed through self-assembly into helicoidal structures similar to cholesteric liquid crystals. The material need to possess a chiral property, i.e. the molecules should be asymmetrical so they don't align parallel but place themselves on top of each other with a twist. The material should furthermore be birefringent where the refractive index is different in one of the 3 main directions. The structure split the light into a left and right handed circular component, where the one is reflected and the other transmitted. Maximum reflectivity is achieved when the distance between planes with parallel material threads (this is a $1 / 2$ pitch) is equal to $1 / 2$ wavelength. In chitinous material with a mean refractive index about 1,53 and a half pitch of $165 \mathrm{~nm}$ the structure will reflect bluegreen light with a dominant wavelength of $505 \mathrm{~nm}$. In the beetle cuticle the material threads in a liquid self-assemble into the structure after they are created by the underlying epidermal cells. This is followed by a chemical hardening process that fixates the structure into its lasting condition.

A growing number of layers or helicoidal pitches increase the reflectivity. In the reflecting part of the beetle cuticle the number of layers can be less than 10 but in other cases higher than 100 . The reflectivity depends on the number of layers and the difference in refractive index. If layer thickness is equal throughout the stack a single colour results. Broadband reflection, e.g. white light, is achieved when a range of different layer thicknesses are present. The metallic appearance is a result of very specular reflection, i.e. parallel incoming light is reflected in parallel. This is the normal case for both types of reflectors. More matte or dull appearances is explained as either a light scattering coating or as irregularities in the levelling resulting in light that is reflected in different directions. 
Both structures are iridescent, i.e. the reflected colour change dependent of the viewing angle. However some beetles with structural colours do not have this characteristic. For the silver metallic beetles this can be explained with a reflector that reflects a broader spectrum than the visible. The human eye is therefore not capable of detecting the iridescence. For narrower band reflectors the explanation can be irregularities, e.g. tiny pits in the cuticle.

The specific properties of the structure like colour, reflectivity and sensibility to viewing angle can be designed by adjusting base materials, orientation of nano-fibres, layer thickness/pitch and variation of layer thickness.

Whether the built up process starts from the inside as seen in the beetle cuticle where the outer layers are formed first, does not seem to be the crucial feature of the structure. However, the built up of cholesteric liquid crystals requires that the crystals go through phases from fluid to semi fixed.

Major challenges in the further work include the identification of relevant basic materials that are suitable for coatings. The materials must be transparent, and be available with two different refractive indices. In order to be applied as a coating they must be fluid and be able to become solid once applied. For the helical structures the materials should possess chirality and be birefringent. Another significant challenge is to determine the mechanism of deposition and how to control and tune the layer thickness within the coating. In order to control the degree of iridescence a detailed understanding of micro-structural irregularities is required. This is a complex process involving competences from design methodology, materials science, surface technology and optical physics.

\section{ACKNOWLEDGEMENTS}

We thank the Zoological Museum at Copenhagen University for the loan of beetles, Mr. Thomas Nissen and Mr. Thomas Winkel for the making of illustrations and Prof. Sven Oluf Andersen, Copenhagen University for valuable discussions. 


\section{REFERENCES}

[1] H.E. Hinton, Symp. R. Ent. Soc. Lond. 1970, 5, 41.

[2] H.E. Hinton, D.F. Gibbs, J. Insect Physiol. 1971, 17, 1023.

[3] H.E. Hinton, in: The Insect Integument (ed: H.R. Hepburn), Elsevier, Amsterdam - Oxford New York., 1976, 475.

[4] S. Kinoshita,S. Yoshioka, K. Kawagoe, Proc. R. Soc. Lond. 2002 B 269, 1417.

[5] J.S. Ishay, L. Litinetsky, V. Persis, Z. Barkay, E. Ben-Jacob, J. Elec Micr. 2002, 51-1, 79.

[6] S. Berthier, Iridescences - les couleurs physiques des insects, Springer Paris, 2003.

[7] P. Vukusic, R. Sambles, Nature 2003, 424, 852.

[8] P. Vukusic, I. Hooper, Science 2005, 310, 1151

[9] A. Argyros, S. Manos, M.C.J. Large, D.R. McKenzie, G.C. Cox, D.M. Dwarte, Micron. 2002, 33, 483.

[10] M. Rothschild, B. Gardiner, R. Mummery, J. Zool., Lond. 1978, 186, 351.

[11] A.C.Neville, J. Insect Physiol. 1977, 23, 1267.

[12] S. Caveney, Proc. Roy. Soc. Lond. B. 1971, 178, 205.

[13] A.C. Neville, Biology of the Arthropod Cuticle, Springer-Verlag, Berlin Heidelberg New York, 1975.

[14] S. Kinoshita, S. Yoshioka, ChemPhysChem 2005, 6, 1443.

[15] P. Beckmann, Color and Texture of Beetles, www.living-jewels.com/color.htm, as on 3. December 2006.

[16] J. Schmidt, Prey acquisition and Predator Avoidance by Tiger Beetles (Coleoptera:

Cicindelidae), www.colostate.edu/Depts/Entomology/courses/en507/papers_2001/schmidt.htm, as on 3. December 2006.

[17] S. Berthier, Iridescences - The Physical Colors of Insects, Springer, 2007.

[18] B. Moussian, H. Schwarz, S. Bartoszewski, C. Nüsslein-Volhard. J. Morphology 2005, 264, 117.

[19] S. Gorb, Attachment Devices of Insect Cuticle, Kluwer Academic Publishers, London. 2001.

[20] H.R. Hepburn, in Comprehensive insect physiology, biochemistry and pharmacology, Vol. 3, (eds. G.A. Kerkut, L.I. Gilbert), Pergamon Press 1985.

[21] S. Gorb, Y. Jiao, M. Scherge, J. Comp Physiol A 2000, 186, 821.

[22] K. M. Rudall, in The Insect Integument (ed. H.R. Hepburn), Elsevier Amsterdam, 1976, 21.

[23] P. Wang, R.R. Granados, Arch. Insect Biochem. Physiol. 2001, 47, 110-118.

[24] J. Chen, Q.-Q. Ni, Y. Xu, M. Iwamoto, Composite Structures 2007, 81, 432.

[25] T.D. Schultz, M.A. Rankin, J. Exp. Biol. 1985, 117, 87.

[26] M. Kurachi, Y. Takaku, Y. Komiya, T. Hariyama, Naturwissenschaften 2002, 89, 295.

[27] B. Kostron, K. Marquardt, U. Kaltenhauser, H.W. Honegger, J. Insect Physiol 1995, 41-12, 1045.

[28] J.P. Vigneron, M. Rassart, C. Vandenbem, V. Lousse, O. Deparis, L.P. Biró, D. Dedouaire, A. Cornet, P. Defrance, Physical Review E 2006, 73-041905, 1.

[29] A. Parker, D.R. McKenzie, M.C.J. Large, J. exp. biol. 1998, 201, 1307.

[30] D. Mossakowski, Journal of Microscopy 1979, 116-3, 351.

[31] H. Durrer, W. Villiger, J. Insect. Morph. Embryol. 1972, 1233.

[32] A.C. Neville, S. Caveney, Biol. Rev. 1969, 44, 531. 
[33] A.G. Richards, F.H. Korda, Biol. Bull. 1948, 94-3, 212.

[34] S.A. Shaikh, M.V. Deshpande, World J. Microbiol. Biotech. 1993, 9, 468.

[35] H.E. Hinton, Proc. Br. ent. nat. Hist. Soc. 1973, 6, 43.

[36] H. Merzendorfer, J Comp Physiol B 2006, 176, 1.

[37] W.L. Tower, Biol. Bull. 1906, 10-4, 176.

[38] S.O. Andersen, in Comprehensive insect physiology, biochemistry and pharmacology, Vol. 3, (eds. G.A. Kerkut, L.I. Gilbert), Pergamon Press Oxford, 1985, 59.

[38] H. Merzendorfer, L. Zimoch, J. Exp. Biol. 2003, 206, 4393.

[39] T. D. Schultz, M. A. Rankin, J. Exp. Biol. 1985, 117, 111.

[40] S. Ostrowski, H. A. Dierick, A. Bejsovec, Genetics 2002, 161, 171.

[41] B. Moussian, E. Tång, A. Tonning, S. Helms, H. Schwarz, C. Nüsslein-Volhard, A.E. Uv, Development 2005, 133, 163.

[42] P. Vukusic, R.J. Wootton, J.R. Sambles, Proc. R. Soc. Lond. B 2004, 271, 595.

[43] J.F.V. Vincent, Composites: Part A 2002, 33, 1311.

[44] J.F.V. Vincent, U.G.K. Wegst, Arthropod Struct. \& Develop. 2004, 33, 187.

[45] S.J. Harnodrakas, J.H. Willis, V.A. Iconomidou, Insect. Biochem. Mol. Biol. 2002, 32, 1577.

[46] V.A. Iconomidou, J.H. Willis, S.J. Hamodrakas, Biochem. Mol. Biol. 2005, 35, 553

[47] D. Raabe, C. Sachs, P. Romano, Acta Materialia 2005, 53-15, 4281.

[48] A.C. Neville, Biology of fibrous composites, Cambridge U.P. 1993.

[49] M.M. Giraud-Guille, Cur. Op. Sol. 1998, 3, 221.

[50] D. Raabe, P. Romano, C. Sachs, A. Al-Sawalmih, H.-G. Brokmeier, S.-B.Yi, G. Servos, H.G.Hartwig, J. Crystal Growth. 2005, 283, 1.

[51] A.C. Neville, B.M. Luke, J. Insect Physiol. 1971, 17, 519.

[52] D. Raabe, P. Romano, C. Sachs, H. Fabritius, A. Al-Sawalmih, S.-B. Yi, G. Servos, H.G. Hartwig, Materials Science and Enginering A 2006, 421, 143.

[53] E. Belamie, P. Davidson, M.M. Giraud-Guille, J. Phys. Chem. B 2004, 108, 14991.

[54] M.M. Giraud-Guille, L. Besseau, R. Martin, Journal of Biomechanics 2003, 36, 1571.

[55] S.B. Murray, A.C. Neville, Int. Jour. Biol. Macromol. 1998, 22, 137.

[56] Jr. Anderson Pace, Science, New Series. 1972 176-4035, 678.

[57] Y. Bouligand, J.-P. Denefle, J.-P. Lechaire, M. Maillard, Biol. Cell. 1985, 54, 143.

[58] L. Besseau, Y. Bouligand, Tissue \& Cell 1998, 30-2, 251.

[59] Y. Bouligand, Tissue \& Cell 1972, 4-2, 189.

[60] R.A. Steinbrecht, H. Scharf, Zeiss Inform. 1986, $28,36$.

[61] K.J. Kramer, D. Koga, Insect Biochem. 1986 16-6, 851.

[61] R.A. Steinbrecht, W. Mohren, H.K. Pulker, D. Schneider, Proc. R. Soc. Lond. B 1985, 226, 367.

[62] A.G. Richards, The Integument of Arthropods, The University of Minesota Press, 1951.

[63] N. Kato, C.R. Mueller, J.F. Fuchs, V. Wessely, Q. Lan, B.M. Christensen, Insect Biochem. Mol. Biol. 2006, 36-1, 1.

[64] M. Burret, A. Boevé, J.-L.Barker, M. Spindler-Barth, Tissue and Cell 2005, 37, 67.

[65] M. Zhang, A. Haga, H. Sekiguchi, S. Hirano, Int. J. Biological Macromolecules 2000, 27, 99.

[66] W.G. Goodman, The Food Insects Newsletter 1989, 2-3, 2.

[67] H.K. Noh, S.W. Lee, J.-M. Kim, J.-E. Oh, K.-H. Kim, C.-P. Chung, S.-C. Choi, W.H. Park, B.M. Min, Biomaterials 2006, 27, 3934. 
[68] H.-M. Cauchie, Hydrobiologia 2002, 470, 63.

[69] W.R. Terra, Arch. Insect Biochem. Physiol. 2001, 47, 47.

[70] N.F.C. Secundino, I. Eger-Mangrich, E.M. Braga, M.M. Santoro, P.F.P. Pimenta, J. Med. Entomol. 2005, 42-6, 928.

[71] P. Compère, M.-F. Jaspar-Versali, G. Goffinet, Biol. Bull. 2002. 202, 61.

[72] S.O. Andersen, Insect Biochemistry and Molecular Biology 2001, 31-4-5, 445.

[73] Y. Bouligand, C. R. Palevol 2004, 3, 617.

[74] F.R.S. Lord Rayleight, Roy. Soc. Proc. A 1923, 102, 668.

[75] R.A. Steinbrecht, Tissue and Cell 1985, 17-5, 745.

[76] R. Tilley, Colour and Optical Properties of Materials, John Wiley \& Sons 2000.

[77] M.F. Land, in: Progress in Biophysics and Molecular Biology (ed. J.A.V. Buttler), Pergamon Press, Oxford, 1972, 75.

[78] A.F. Huxley, J. Exp. Biol. 1968, 48, 227.

[79] M.F. Land, J. exp. Biol. 1966, 45, 433.

[80] H.A. Macleod, Thin film optical filters, Institute of Physics Publishing, Bristol and Philadelphia, 2001.

[81] M. Born, E. Wolf, Principle of Optics, Cambridge University Press, 1999.

[82] A.R. Parker, J. Opt. A: Pure Appl. Opt. 2000, 2, R15.

[83] H. Onslow, Phil. Trans. R. Soc. Lond. 1923, B 211, 1.

[84] S.O. Andersen, Univ. of Copenhagen, personal communication, 2006.

[85] J.P. Vigneron, J.-F. Colomer, N. Vigneron, V. Lousse, Physical Review E 72, 2005, 061904, 1.

[86] P. Vukusic, J.R. Sambles, C.R. Lawrence, R.J. Wootton, Proc. Biol. Sci. 1999, 266-1427, 1403.

[87] P. Vukusic, R. Sambles, C. Lawrence, G. Wakely, Applied Optics. 2001, 40-7, 1116.

[88] Y. Bouligand, J. Microscopie 1971,11, 441.

[89] A.C. Neville, in: Cuticle Techniques in Arthropods (ed. T.A. Miller), Springer-Verlag NY, 1980, 1.

[90] I.J. Hodgkinson, L. De Silva, P. Murray, Q.H. Wu, M. Arnold, Proc of SPIE 2004, 5509, 15.

[91] E. Hecht, Optics, Addison \& Wesley, 2000.

[92] M. Srinivasarao, Chem. Rev 1999, 99, 1935.

[93] S. Chandrasekhar, Rep. Prog. Phys. 1976, 39, 613.

[94] L.M. Mäther, M.F. Land, U.E. Siebeck, N.J. Marshall, J. Exp. Biol. 2003, 206, 3607.

[95] N. A. Locket, Proc. Roy. Soc. Lond. B. 1972, 182-1067, 249.

[96] A. Bigi, M. Burghammer, R. Falconi, M.H.J. Koch, S. Panzavolta, C. Riekel, J. Struct. Biol. 2001, 136, 137.

[97] M.M. Giraud-Guille, E. Belamie, G. Mosser, C. R. Palevol. 2004, 3, 503.

[98] T. Yarnamoto, T. Domon, S. Takahashi, N. Islam, R. Suzuki, Anat. Embryol. 2000, 202, 25.

[99] D.E. Birk, R.L. Trelstad, The Journal of Cell Biology 1984, 99-6, 2024.

[100] K.S. Gould, D.W. Lee, Am. J. Botany 1996, 83-1, 45.

[101] T. Moogan, Nature Biotechnol. 2006, 24-4, 421.

[102] A. Bobrowsky, V. Shibaev, J. Stumpe, J. Phys. Chem. 2006, 110, 2331.

[103] C. Bustamante, M.F. Maestre, I. Jr. Tinoco, J. Chem. Phys. 1980, 73-9, 4273.

[104] R. Lemberg, Leonardo 1969, 2-1, 45.

[105] J.W. Goodby, Science 1986, 231, 350. 
[106] E. Belamie, G. Mosser, F. Gobeaux, M.M. Giraud-Guille, J. Phys.: Condens. Matter. 2006, 18, 115.

[107] L. Besseau, M.M. Giraud-Guille, J. Mol. Biol. 1995, 251, 197.

[108] M. Meissner, M.G. Peter, J.F.V. Vincent, Biomacromolecules 2001, 2, 369.

[109] T.D. Schultz, G.D. Bernard, Nature 1989, 337, 72.

[110] E. Kikuti, R. Conrrado, N. Bocchi, S.R. Biaggio, R.C. Rocha-Filho, J. Braz. Chem. Soc., 2004 $15-4,472$.

[111] Nakano, http://www.nakano-acl.co.jp/index1.html as on December 4th 2007.

[112] Euro-inox, http://www.euro-inox.org/pdf/build/Finishes02_EN.pdf as on December 4th 2007.

[113] M.D. Cathell, C.L. Schauer, Biomacromolecules, 2007, 8, 33.

[114] M.F. Weber, C.A. Stover, L.R. Gilbert, T.J. Nevitt, A.J. Ouderkirk, Science 2000, 287, 2451.

[115] K. Iohara, M. Yoshimura, H. Tabata, S. Shimizu, Chemical Fibers International 2000, 50-1, 38.

[116] J. Heinlein, M. Kasch, Paint and coatings industry 1999, 15-8, 58.

[117] L.H. Shu, T.A. Lenau, H.N. Hansen, L. Alting, CIRP-annals, 2003, 52-1, 101. 
The present paper presents a cross disciplinary biomimetic review of research results that explain the materials and nanostructure in beetle shells and the mechanisms that generate them. The paper also presents a review of existing applications with structural colours obtained by nano-structured surfaces and describes the goals for further research required in order to achieve industrially manufactured beetle-like surfaces with properties such as sustainability, aesthetics, insulation, durability etc.

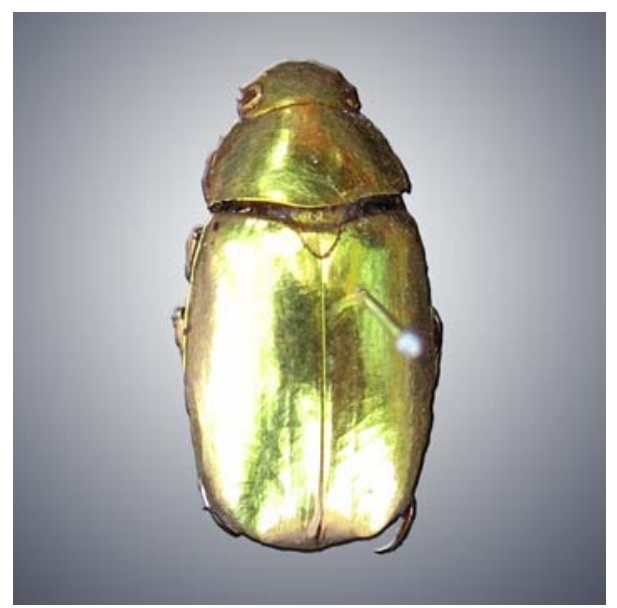

Grafic for the table of content.

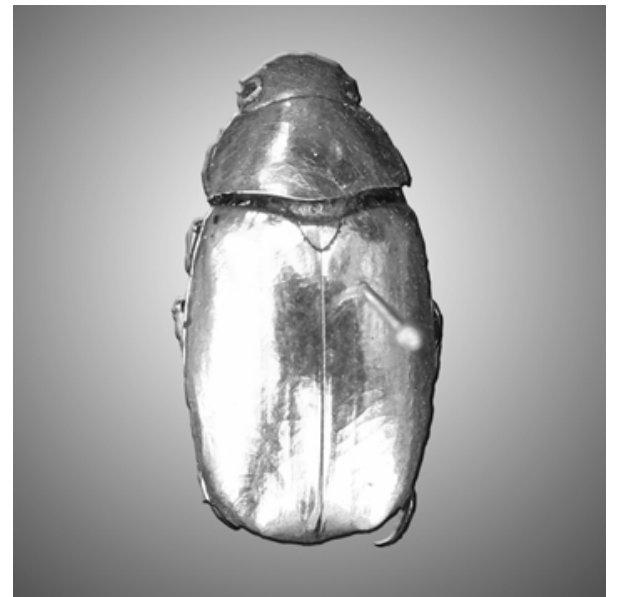

Alternative grafic for the table of content 